\title{
Maple Bark Biochar Affects Rhizoctonia solani Metabolism and Increases Damping-Off Severity
}

\author{
Tanya R. Copley, Konstantinos A. Aliferis, and Suha Jabaji
}

Plant Science Department, McGill University, Ste-Anne-de-Bellevue, Quebec, Canada H9X 3V9.

Accepted for publication 6 April 2015.

\begin{abstract}
Copley, T. R., Aliferis, K. A., and Jabaji, S. 2015. Maple bark biochar affects Rhizoctonia solani metabolism and increases damping-off severity. Phytopathology 105:1334-1346.

Many studies have investigated the effect of biochar on plant yield, nutrient uptake, and soil microbial populations; however, little work has been done on its effect on soilborne plant diseases. To determine the effect of maple bark biochar on Rhizoctonia damping-off, 11 plant species were grown in a soilless potting substrate amended with different concentrations of biochar and inoculated or not with Rhizoctonia solani anastomosis group 4. Additionally, the effect of biochar amendment on $R$. solani growth and metabolism in vitro was evaluated. Increasing

concentrations of maple bark biochar increased Rhizoctonia damping-off of all 11 plant species. Using multivariate analyses, we observed positive correlations between biochar amendments, disease severity and incidence, abundance of culturable bacterial communities, and physicochemical parameters. Additionally, biochar amendment significantly increased $R$. solani growth and hyphal extension in vitro, and altered its primary metabolism, notably the mannitol and tricarboxylic acid cycles and the glycolysis pathway. One or several organic compounds present in the biochar, as identified by gas chromatography-mass spectrometry analysis, may be metabolized by $R$. solani. Taken together, these results indicate that future studies on biochar should focus on the effect of its use as an amendment on soilborne plant pathogens before applying it to soils.
\end{abstract}

Rhizoctonia solani anastomosis group 4 (AG-4) is an economically important soilborne plant pathogen found worldwide causing damping-off of seedlings and affecting a wide range of plant hosts (González García et al. 1999). Seedling losses in greenhouse settings can reach up to 92\% (Anderson 1982; Bailey et al. 2003). Because only a few resistant plant varieties exist, crop protection against $R$. solani mainly relies on pesticides (Huang et al. 2012). Even though biological control methods exist, their effectiveness varies (Huang et al. 2012; Montealegre et al. 2003). Therefore, alternative control methods need to be developed to combat the pathogen.

Peat, the most common organic substrate, is used as a standard greenhouse practice for germinating seedlings. Although common peat potting substrates are capable of suppressing some soilborne pathogens, studies reported inconsistencies in their ability to suppress Rhizoctonia damping-off (Bonanomi et al. 2010; Pane et al. 2011; Scheuerell et al. 2005). The discrepancy in the results demonstrates that more studies are required to determine if organic soil amendments can be used to manage Rhizoctonia damping-off, particularly in conducive potting media such as peat.

Biochar is a charcoal by-product of pyrolysis, a process used in the production of biofuel using residual biomass (Lehmann et al. 2006). Benefits that can accrue from the use of biochar as a soil amendment in agriculture are wide ranging, including improvement in soil fertility and structure, sequestration of carbon to mitigate climate change as well as enrichment of beneficial soil microorganisms (Khodadad et al. 2011; Kolton et al. 2011; Lehmann et al. 2006; Lehmann and Joseph 2009).

Based on the chemical and physical soil improvements reported following biochar amendments to soils (Lehmann et al. 2006; Sohi

Corresponding author: S. Jabaji; E-mail address: suha.jabaji@mcgill.ca

*The $\boldsymbol{e}$-Xtra logo stands for "electronic extra" and indicates that one supplementary figure and three supplementary tables are published online.

http://dx.doi.org/10.1094/PHYTO-08-14-0231-R

(C) 2015 The American Phytopathological Society et al. 2010), soil microbial communities including frequency and abundance of plant pathogens will likely be altered. In addition, increases in certain components within microbial communities cause induced systemic resistance (ISR) responses in plants resulting in increased resistance to plant diseases (Benhamou et al. 1998; Van Peer et al. 1991). Applications of biochar to soilless potting substrates have been reported to reduce the severity of foliar diseases such as powdery mildew, anthracnose and gray mold, and decrease damage caused by arthropod pests (Elad et al. 2010; Harel et al. 2012). These effects could be a result of compounds present in the biochar, which directly affect plant systemic acquired resistance (SAR) causing plant priming upon biochar amendment (Harel et al. 2012) or indirectly, by biochar-related alterations in the soil microbial community (Graber et al. 2010; Kolton et al. 2011; Rillig et al. 2010; Warnock et al. 2010), which may prime plants via ISR pathways. However, results from studies examining biochar effects on fungal root diseases are inconsistent. For example, diseases caused by certain soilborne pathogens were suppressed by the addition of biochar (Elmer and Pignatello 2011), while others increased at greater biochar concentrations (Elmer and Pignatello 2011; Jaiswal et al. 2014), or increased pathogen soil populations without causing an increase in disease (Gravel et al. 2013). These inconsistencies dictate the need for research examining the effect of biochar on pathogenic fungi alone and in the context of soil microbial communities.

To date, no studies have been published examining the effects of biochar on Rhizoctonia damping-off severity in various plant species or whether biochar has a direct effect on the growth and metabolism of $R$. solani. As there are few comparative studies on the effect of biochar on agricultural crops in the presence of a root pathogen, the overarching goal of this study was to determine whether the amendment of a commercially available biochar to a peat-based soilless potting substrate can suppress Rhizoctonia damping-off disease of several plant species. We also investigated the direct effect of biochar on the growth rate of $R$. solani and whether its metabolism was affected by biochar amendment. 


\section{MATERIALS AND METHODS}

Biochar physicochemical characteristics. Biochar, supplied by Award Rubber \& Plastic Industries Ltd. (Plessisville, Canada), made from the pyrolysis of maple wood bark at $700^{\circ} \mathrm{C}$ for $4 \mathrm{~h}$ was used as an amendment. The biochar was ground and sieved to particle sizes $\leq 1 \mathrm{~mm}$. It was analyzed for $\mathrm{pH}$ and electrical conductivity (EC) in $0.01 \mathrm{M} \mathrm{CaCl}_{2}$ at a ratio of 1:2, wt/vol, biochar/solution (Gavlak et al. 2003), cation exchange capacity (CEC) using the $\mathrm{BaCl}_{2}$ method (Gillman and Sumpter 1986), percent water holding capacity (\%WHC) by saturating with water and letting the water drain until the mass remained stable at 15 bar (Rawls et al. 1982), and initial water content by baking at $70^{\circ} \mathrm{C}$ for $72 \mathrm{~h}$. The initial $\mathrm{pH}$ and the electric conductivity (EC) were measured before and after mixing into the potting substrate.

Maple wood biochar was characterized chemically and physically in order to define the material as completely as possible. The elemental composition of biochar powder was characterized in three separate subsamples by inductive coupled plasma atomic emission spectroscopy (ICP-AES model Vista [axial], Varian Inc., Cary, NC)] using hot nitrous acid dissolution at a final concentration of 5\% for trace elements, while carbon, nitrogen, hydrogen and sulfur were analyzed by CHNS (LECO CHNS model 932, Richmond Scientific, St.-Joseph, MI) using vanadium pentoxide as an oxidizer at the Institut national de recherche scientifique (INRS, Québec, Canada).

For GC/MS analysis, organic compounds were extracted by grinding the biochar $(500 \mathrm{mg})$ in a mortar using a pestle in $1.5 \mathrm{ml}$ of methanol/ethyl acetate $(1: 1, \mathrm{vol} / \mathrm{vol})$ (HPLC grade, Fisher Scientific, Ottawa, Canada) followed by shaking on an orbital shaker at $250 \mathrm{rpm}$ at room temperature for $2 \mathrm{~h}$. The suspension was filtered through $0.2 \mu \mathrm{m}$ filters (Millex-FG, Millipore, MA) and evaporated to dryness using a Labconco CentriVap refrigerated vacuum concentrator equipped with a cold trap (Labconco, Kansas City, MO).

Dried samples were derivatized as previously described (Aliferis and Jabaji 2012). Briefly, $80 \mu \mathrm{l}$ of a methoxylamine hydrochloride solution (20 mg ml-1 in pyridine) (Sigma-Aldrich Canada, Ltd., Oakville, Canada) was added to the sample and incubated at $30^{\circ} \mathrm{C}$ for $120 \mathrm{~min}$, followed by the addition of N-methyl-N-(trimethylsilyl) trifluoroacetamide (MSTFA, $80 \mu \mathrm{l}$ ) (Sigma-Aldrich) and incubated at $37^{\circ} \mathrm{C}$ for $90 \mathrm{~min}$. Prior to GC/MS analyses derivatized samples were kept at room temperature in the dark for $24 \mathrm{~h}$. Finally, the derivatized samples were added in microinserters $(150 \mathrm{ml}$, Fisher Scientific) inside of glass autosampler vials $(2 \mathrm{ml})$.

An Agilent 7890A GC system (Agilent Technologies, Inc., Santa Clara, CA) coupled with a 5975C series mass selective detector (MSD) and a 7693A series autosampler were employed. Parameters for the analysis were similar to the ones previously described (Aliferis and Jabaji 2012). Briefly, electron ionization at $70 \mathrm{eV}$ was used and full scans were acquired at the mass range of 50 to $800 \mathrm{Da}$ at 1 scan s$^{-1}$ with a 10 min solvent delay. The temperatures were $150^{\circ} \mathrm{C}$ for the ion source, $230^{\circ} \mathrm{C}$ for the transfer line, $230^{\circ} \mathrm{C}$ for the injector, initial oven temperature of $70^{\circ} \mathrm{C}$ stable for $5 \mathrm{~min}$, followed by a $5^{\circ} \mathrm{C} \mathrm{min}-1$ increase to $310^{\circ} \mathrm{C}$, and finally stabilized for $1 \mathrm{~min}$. An HP-5MS ultra inert (UI) capillary column $(30 \mathrm{~m}$, i.d. $0.25 \mu \mathrm{m})$ (Agilent Technologies, Inc.) was used and helium was the carrier

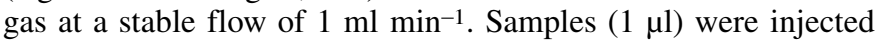
performing a standard on column injection with a split ratio of 10. Calibration of the instrument was performed using the default automatic calibration mode as recommended by the manufacturer and additionally by analyzing the DRO/GRO Range Calibration Standard (Restek Corporation, Bellefont, PA) for monitoring of the analyzer's performance. Chromatogram deconvolution was performed using the Agilent MSD Chemstation version E.02.00.493 and mass spectra searches using the libraries of the National Institute of Standards and Technology 08 (NIST 08). The absolute identification of metabolites was based on matching mass spectra and retention times (RT) to those of selected analytical standards analyzed on the same platform with the same analytical method following the guidelines of the metabolomics standards initiative (Sansone et al. 2007).

Pathogen growth and inoculum preparation. An extremely pathogenic isolate of $R$. solani, isolate A76, belonging to anastomosis group AG-4 was obtained from M. Cubeta, University of North Carolina. The isolate was produced on oat kernels according to the method of Cardoso and Echandi (1987). Briefly, 1-week-old $R$. solani cultures were covered with a single layer of sterile oat kernels and allowed to fully colonize the kernels for 2 weeks. After 2 weeks of growth, the colonized kernels were removed from the petri plates, air dried for $30 \mathrm{~min}$ and kept at $4{ }^{\circ} \mathrm{C}$ in the dark for future experiments. Starter cultures for inoculum production were produced by placing one colonized oat kernel on potato dextrose agar (PDA; Difco Laboratories, Detroit, MI) in petri dishes incubated at $24^{\circ} \mathrm{C}$ in the dark for 1 week. A $5 \mathrm{~mm}$ plug was then transferred to a PDA plate on which the culture was kept for 1 week. Dehulled millet seed was sterilized in an autoclave at $120^{\circ} \mathrm{C}, 15$ p.s.i. for $20 \mathrm{~min}$ on three consecutive days and was placed as a single layer on the surface of the actively growing 1 -week-old $R$. solani culture. The culture was allowed to colonize the millet seed for 2 weeks and a fully colonized millet seed was used as the inoculum for plant infection experiments. Sterile millet seed placed on sterile PDA plates for 2 weeks served as the control for mock-inoculation experiments. All cultures were incubated at $24^{\circ} \mathrm{C}$ in darkness.

In another set of experiments, we tested whether $R$. solani infectivity differed when the fungus was first grown on biocharamended medium and then used as inoculum. The strain A76 was grown on cellophane membranes overlaid over water agar (WA) plates, $\mathrm{pH} 7.5$, amended with $0,1,3$, or $5 \%$, wt/vol, biochar for 5 days. Briefly, biochar was added to the WA and the $\mathrm{pH}$ adjusted over several hours until it was stable at 7.5. The medium was then autoclaved for $20 \mathrm{~min}$. Inoculum consisted of cellophane squares $\left(0.25 \mathrm{~cm}^{2}\right)$ covered with actively growing hyphae on biochar amended or nonamended culture plates and the squares were used as the inoculation source. Cellophane squares $\left(0.25 \mathrm{~cm}^{2}\right)$ from noninoculated plates were used for control treatments.

Plant inoculation and damping-off evaluation. Experiment 1. Seeds of 11 plant species (Table 1) were obtained from commercial seed companies and surface sterilized in $30 \%$ hydrogen peroxide for $5 \mathrm{~min}$ followed by three rinses in sterile water. Seed was then imbibed on damp filter paper until the root radical emerged from the seed coat ( 2 to 7 days depending on the plant species). Ten pregerminated seeds were placed in either a $9 \mathrm{~cm}$ (all seedlings except pea, soybean, and cucumber) or in a $15 \mathrm{~cm}$ (pea, soybean, and cucumber) petri dish approximately $0.5 \mathrm{~cm}$ from the edge of the

TABLE 1. Plant species and sources used for experiments

\begin{tabular}{|c|c|c|}
\hline Plant species & Cultivar & Companyz \\
\hline Soybean (Glycine $\max (\mathrm{L}$.$) Merr.)$ & Savannah & 1 \\
\hline Pea (Pisum sativum L.) & $\begin{array}{l}\text { UT230 Improved } \\
\text { Laxton's }\end{array}$ & 2 \\
\hline Sugar beet (Beta vulgaris L.) & Bronco & 2 \\
\hline Alfalfa (Medicago sativa L.) & $\begin{array}{l}\text { Vendor would not } \\
\text { disclose }\end{array}$ & 3 \\
\hline $\begin{array}{l}\text { Sweet pepper (Capsicum } \\
\text { аппиит L.) }\end{array}$ & California Wonder & 3 \\
\hline $\begin{array}{l}\text { Tomato (Solanum } \\
\text { lycopersicum L.) }\end{array}$ & Beefstake & 3 \\
\hline Lettuce (Lactuca sativa L.) & Paris Island Cos & 3 \\
\hline Cucumber (Cumis sativus L.) & Straight Eight & 3 \\
\hline Leek (Allium ampeloprasum L.) & Albana & 4 \\
\hline $\begin{array}{l}\text { Carrot (Daucus carota sativus } \\
\text { (Hoffm.) Schübl. \& G. Martens) }\end{array}$ & Touchon & 4 \\
\hline Radish (Raphanus sativus L.) & Hybrid Fluo & 4 \\
\hline
\end{tabular}

z Company names and locations are as follows: 1, RDR Proulx Grains and Seed, Nicolet, Canada; 2, Stokes, Thorold, Canada; 3, Veseys, Charlottetown, Canada; and 4, W. H. Perron, Laval, Canada. 
dish. Petri dishes contained either $40 \mathrm{ml}$ ( $9 \mathrm{~cm}$ petri dishes) or $120 \mathrm{ml}(15 \mathrm{~cm}$ petri dishes) soilless potting substrate consisting of AgroMix G10 (Fafard Ltd., St. Bonaventure, Canada) and sand $(1: 1, \mathrm{vol} / \mathrm{vol}$ ) amended with $0,1,3$, or $5 \%$ (wt/wt) biochar (equivalent to approximately $0,25,75$, and 125 tons ha $^{-1}$, respectively) by homogenously mixing the biochar throughout the potting substrate prior to planting seed. These concentrations were similar to those used in other studies examining the effects of biochar on plants grown in soilless potting substrates. The substrate in the 9 and $15 \mathrm{~cm}$ petri dishes was then moistened with either 20 or $60 \mathrm{ml}$ of sterile water, respectively. Seedlings were inoculated by placing a fully colonized millet seed in the center of the petri dish, or mock-inoculated with a sterile millet seed. Petri dishes were placed at $24^{\circ} \mathrm{C}$ in the dark for 5 days. The experiment consisted of 88 treatments ( 4 biochar rates $\times 2$ inoculations $[R$. solani or mock-inoculated controls] $\times 11$ plant species) with three replicates (petri dishes) per treatment. Each replicate consisted of 10 seedlings.

Experiment 2. For the effect of biochar on $R$. solani infectivity, only two plant species (soybean and sugar beet) were used. Seed was prepared in the same manner as described in experiment 1 and placed in petri dishes containing either $40 \mathrm{ml}$ ( $9 \mathrm{~cm}$ petri dishes) or $120 \mathrm{ml}$ ( $15 \mathrm{~cm}$ petri dishes) of AgroMix G10 soilless potting substrate and sand $(1: 1, \mathrm{vol} / \mathrm{vol})$. No biochar was added to the substrate, as the aim was to examine the effect of prior exposure of $R$. solani to biochar on its virulence. Petri dishes were then inoculated with a $0.25 \mathrm{~cm}^{2}$ cellophane membrane placed in the center of the plate with hyphae of $R$. solani previously exposed to WA containing either $0,1,3$, or $5 \%$ biochar (wt/vol). Controls were mock-inoculated with $0.25 \mathrm{~cm}^{2}$ cellophane pieces from petri dishes containing WA amended with $0,1,3$, or $5 \%$ biochar (wt/vol). The experiment consisted of 16 treatments [ 4 biochar amended WA rates $\times$ 2 inoculations ( $R$. solani or mock-inoculated controls) $\times 2$ plant species] with 3 replicates (petri dishes) per treatment. Each replicate consisted of 10 seedlings. Both experiments (1 and 2) were performed twice. Petri dishes were placed in a completely randomized design for each plant species during each trial for each experiment.

Postemergence damping-off for experiments 1 and 2 was determined 5 days after inoculation using the visual scale of 0 to 5 developed by Cardoso and Echandi (1987), where: $0=$ no visible lesions; $1=$ lesions $\leq 2.5 \mathrm{~mm} ; 2=$ lesions $>2.5$ to $5.0 \mathrm{~mm} ; 3=$ lesions $>5.0 \mathrm{~mm} ; 4=$ lesions girdling plant; or $5=$ plants wilted or dead. Disease severity was determined in each petri dish by taking the average disease score for each petri dish. Disease incidence was determined by calculating the percentage of infected plants per petri dish irrespective of lesion size. At the end of the experiment EC and $\mathrm{pH}$ of the soilless potting substrate were measured and seedling length was recorded. Seedlings and a portion of the substrate from each treatment were flash frozen in liquid nitrogen and stored at $-20^{\circ} \mathrm{C}$ for DNA extraction. Another portion of the substrate was kept for culturable microbe abundances.

DNA extraction from plant tissue and potting substrate. From experiment 1, 10 plants per petri dish were pooled together resulting in six replicates per treatment. Plant DNA was extracted from $100 \mathrm{mg}$ wet weight using the DNeasy Plant Mini Kit (Qiagen, Toronto, Canada) following the manufacturer's protocols with a $1 \mathrm{~h}$ incubation at $65^{\circ} \mathrm{C}$. DNA from $250 \mathrm{mg}$ of each soilless potting substrate amended with 0,1 , and $5 \%$ biochar for each plant species was ground to a fine powder using liquid nitrogen and extracted using the Power Soil DNA Isolation Kit (MoBio, Carlsbad, CA). To determine the extraction efficiency and possible polymerase chain reaction (PCR) inhibition in the soilless potting substrate DNA, samples were spiked with $1,000 \mathrm{ng}$ of pea DNA prior to DNA extraction. The manufacturer's protocols were followed, except that samples were incubated at $65^{\circ} \mathrm{C}$ for $30 \mathrm{~min}$ with vortexing for $30 \mathrm{~s}$ every $6 \mathrm{~min}$. Six soilless potting substrate DNA extractions were done for each biochar treatment for each plant species.
Conventional and quantitative PCR experiments. Prior to quantitative PCR (qPCR) assays, DNA from all infected seedlings and from inoculated soilless potting substrate samples were tested in conventional PCR using the universal eukaryote internal transcribed spacer (ITS) primers ITS4 and ITS5 (White et al. 1990) in order to ensure that the DNA was amplifiable. Each reaction was prepared as previously described (Gagne-Bourgue et al. 2013) with the addition of $2 \mathrm{mg} \mathrm{ml}^{-1}$ of bovine serum albumin (BSA) and 3\% dimethyl sulfoxide (DMSO) to minimize inhibition by PCR inhibitors and DNA secondary structures in the PCR reaction, respectively. A total of $20 \mathrm{ng}$ of plant DNA or $100 \mathrm{ng}$ of soilless potting substrate DNA was used per reaction. The thermal cycling conditions recommended by Fermentas (Fermentas, Thermo Scientific, San Jose, CA) with an annealing temperature of $60^{\circ} \mathrm{C}$ and a total of 40 thermocycles were used. PCR reactions were run with a positive control and a negative control containing no template DNA.

The absolute amount of $R$. solani DNA present in seedlings and soilless potting substrate was quantified using quantitative PCR. DNA was amplified with the $R$. solani-specific forward primer GMRS4 (5'-CGGTTCATCTGCATTTACCTT-3') and reverse compliment of primer GMRS3 (reverse compliment GMRS3-R: 5'AGTGTTATGCTTGGTTCCACT-3') (Johanson et al. 1998) yielding an amplicon of $88 \mathrm{bp}$. Additionally, the plant-specific rbcl primers $1 \mathrm{~F}$ (5'-ATGTCACCACAAACAGAAAC-3') and 724R (5'-TCGCATG TACCTGCAGTAGC-3') (Fay et al. 1997) were used as a normalization gene for all samples including the plant-spiked soilless potting substrate samples. Each $25-\mu \mathrm{l}$ reaction contained $0.25 \mu \mathrm{M}$ each primer, $2 \mathrm{mg} \mathrm{ml}^{-1}$ of BSA, $3 \%$ DMSO, and $100 \mathrm{ng}$ of DNA for potting substrates or $250 \mathrm{ng}$ of seedling DNA. The thermocycling profile used was that of Chen et al. (2009) with annealing at $55^{\circ} \mathrm{C}$ for $30 \mathrm{~s}$ for the seedling DNA or $60 \mathrm{~s}$ for the potting substrate DNA, for a total of 40 thermocycles. All plates were run with a standard curve ranging from $10^{9}$ to $10^{3}$ copies of pDrive plasmid DNA (Qiagen) containing an insert of the 88-bp $R$. solani-specific amplicon. All replicates from each trial for each treatment for each plant species were run on the same plate for a total of 3 replicates per treatment on each plate. Plates were repeated for a total of three technical replicates.

Culturable microbe abundances. To determine the effect of biochar and $R$. solani inoculation on culturable microbe abundances in the soilless potting substrate of all plant species (experiment 1), a $1 \mathrm{~g}$ sample (fresh weight) was taken from each replicate for each treatment, mixed with $10 \mathrm{ml}$ of sterile distilled water, and agitated for $30 \mathrm{~min}$ at $250 \mathrm{rpm}$ at room temperature to dislodge the microbes from the soilless potting substrate particles. Tenfold serial dilutions were prepared and $100 \mu \mathrm{l}$ of a previously optimized dilution was plated on nutrient agar amended with streptomycin at $0.1 \mathrm{mg} \mathrm{ml}^{-1}$ (Fisher Scientific, Ottawa, Canada), ampicillin at $0.1 \mathrm{mg} \mathrm{ml}^{-1}$, rifampicin at $0.01 \mathrm{mg} \mathrm{ml}^{-1}$, and chloramphenicol at $0.1 \mathrm{mg} \mathrm{ml}^{-1}$ (Sigma-Aldrich) for general bacteria, or PDA amended with benomyl at $10 \mathrm{mg} \mathrm{ml}^{-1}$ (Laboratories Wilson Ltd., Laval, Canada) for filamentous fungi and yeast CFU counts (Graber et al. 2010). Actinomycetes were quantified on WA, pH 9.5 (Graber et al. 2010). CFUs were counted on a daily basis until $72 \mathrm{~h}$ after plating. Microbe abundances are presented as the average CFUs per gram of soilless potting substrate. Results represent the average of six biological replicates from the two trials resulting in 528 samples (4 biochar amendment concentrations $\times$ 2 inoculations $[R$. solani or control mock-inoculations] $\times 11$ plant species $\times 3$ biological replicates $\times 2$ trials).

Effect of biochar on $\boldsymbol{R}$. solani growth and metabolism. To determine the effect of biochar on $R$. solani growth in vitro, $R$. solani cultures were grown on $9 \mathrm{~cm}$ petri dishes covered with cellophane membranes containing $20 \mathrm{ml}$ of WA amended with biochar $0,1,3$, or $5 \%(\mathrm{wt} / \mathrm{vol})$ and adjusted to $\mathrm{pH} 7.5$. Plates were prepared as previously described. A 6-mm-diameter plug was taken from 1-week-old cultures grown on PDA and placed in the center of the plate. Radial growth was measured at 6 and $12 \mathrm{~h}$, and every $12 \mathrm{~h}$ thereafter for $120 \mathrm{~h}$ or until growth reached the edge of the plate and the linear growth rate determined. Cultures were scraped from the 
membranes at 48, 72, and $120 \mathrm{~h}$, freeze-dried and the dry mass was recorded. Eight petri dishes were used for each biochar treatment and the experiment was repeated three times for a total of 24 plates per treatment.

To determine whether $R$. solani metabolism is affected by biochar, the metabolic profile of $R$. solani grown under the different biochar amendments was recorded. After 5 days of growth on biochar amended $(0,1$, or $5 \%$, wt/vol) WA, $\mathrm{pH} 7.5$, hyphae were collected by gently scraping the hyphae off of the cellophane membrane and freezing immediately in liquid nitrogen. In order to reduce variability, 28 plates were pooled together to make one pooled replicate. In total, six pooled replications were obtained per treatment. The samples were freeze-dried, ground in liquid nitrogen and $100 \mathrm{mg}$ dry mass was used for metabolite analysis. Samples were prepared by adding $1.5 \mathrm{ml}$ of methanol/ethyl acetate $(1: 1$, $\mathrm{vol} / \mathrm{vol})$ and a solution of $20 \mu \mathrm{l}$ of ribitol $\left(0.2 \mathrm{mg} \mathrm{ml}^{-1}\right)$ (SigmaAldrich) in methanol-water (50:50, vol/vol), serving as the internal standard. Samples were prepared and metabolites were determined by GC/MS using the methods previously described. Six replicates and a quality control (QC) sample per treatment were analyzed. QCs were prepared by combining aliquots $(20 \mu \mathrm{l})$ of each biological replicate for each treatment.

Rhizoctonia solani metabolomics analysis was performed as previously described (Aliferis and Jabaji 2010) with the exception that hydrogen was used as the carrier gas (flow rate $1 \mathrm{ml} \mathrm{min}^{-1}$ ), generated by a Parker Balston generator (Parker Hannifin Corporation, Haverhill, MA). Briefly, GC/MS chromatograms were preprocessed for the removal of metabolites not related to the analyzed biological material and integrated using the Agilent's Agilent MSD Chemstation. Finally they were exported as text files (*.txt) to Microsoft Excel for further processing such as, retention time alignment and normalization to the total ion chromatogram (TIC). The obtained data matrix consisted of the biological replicates from the different biochar amendment concentrations (columns) and the relative concentration of the identified metabolites (rows). For the discrimination between the treatments, multivariate analyses

TABLE 2. Characteristics of maple bark biochar (100\%) and potting media containing $0,1,3$, or $5 \%$ (wt/wt) biochar ${ }^{\mathrm{v}}$

\begin{tabular}{lccccc}
\hline Biochar $(\%)^{\mathrm{w}}$ & $\mathrm{CEC}\left(\mathrm{cmol} \mathrm{kg}^{-1}\right)^{\mathrm{x}}$ & $\mathrm{EC}\left(\mathrm{dS} \mathrm{m}^{-1}\right)^{\mathrm{y}}$ & $\%$ WHC & $\mathrm{pH}$ & Initial water content $(\%)$ \\
\hline 100 & $131.4 \pm 12.8 \mathrm{a}$ & $2.55 \pm 0.02 \mathrm{a}$ & $80.3 \pm 5.0 \mathrm{a}$ & $12.9 \pm 0.0 \mathrm{a}$ & \\
0 & $20.3 \pm 1.7 \mathrm{~b}$ & $0.41 \pm 0.02 \mathrm{~b}$ & $6.2 \pm 2.0 \mathrm{~b}$ & $6.2 \pm 0.2 \mathrm{~d}$ & 3.62 \\
1 & $15.1 \pm 1.0 \mathrm{~b}$ & $0.05 \pm 0.02 \mathrm{~d}$ & $11.2 \pm 6.0 \mathrm{~b}$ & $6.9 \pm 0.1 \mathrm{c}$ & NA $^{\mathrm{z}}$ \\
3 & $17.6 \pm 1.6 \mathrm{~b}$ & $0.08 \pm 0.04 \mathrm{~d}$ & $12.1 \pm 3.0 \mathrm{~b}$ & $7.1 \pm 0.1 \mathrm{c}$ & NA \\
5 & $22.4 \pm 2.3 \mathrm{~b}$ & $0.24 \pm 0.00 \mathrm{c}$ & $15.0 \pm 3.0 \mathrm{~b}$ & $7.4 \pm 0.1 \mathrm{~b}$ & NA \\
$P$ value & $<0.0001$ & $<0.0001$ & $<0.0001$ & $<0.0001$ & NA \\
\hline
\end{tabular}

${ }^{v}$ Numbers represent means \pm standard deviations $(n=3)$. Letters represent significant differences within columns according to Tukey's HSD test at $\alpha=0.05$. CEC, cation exchange capacity; EC, electrical conductivity; \%WHC, percent water holding capacity.

${ }^{w}$ Percent biochar $(\mathrm{wt} / \mathrm{wt})$ in the initial soilless potting substrate.

x Centimols per kilogram.

y Deci-Siemens per meter.

${ }^{\mathrm{z}} \mathrm{NA}$ indicates not applicable, test was not done.

TABLE 3. GC/MS analysis of maple bark biochar pyrolyzed at $700^{\circ} \mathrm{C}$

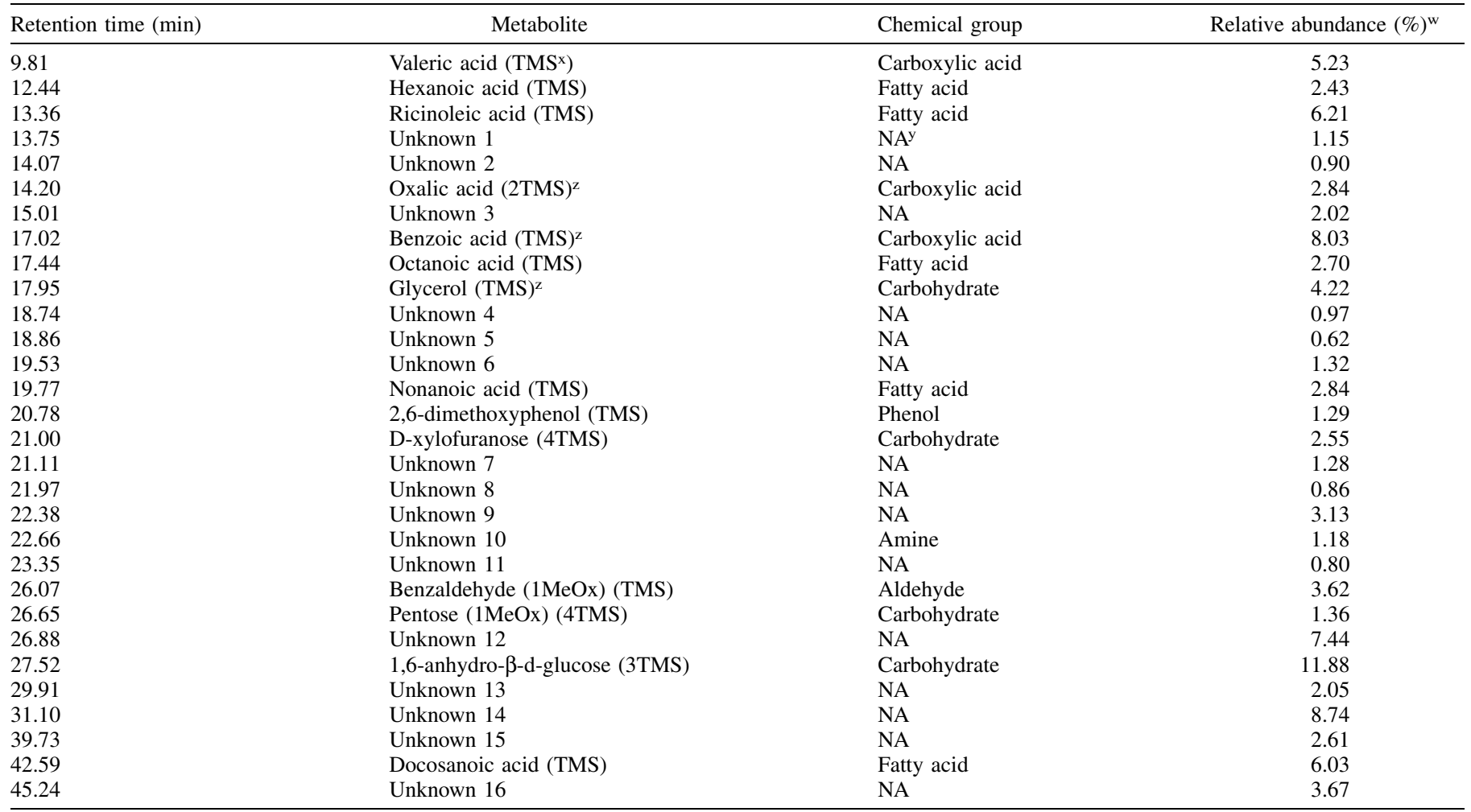

w Relative abundance of the most abundant metabolites detected in the recorded metabolite profiles of biochar. Abundance is expressed by the integral of the chromatographic peaks.

x TMS: Trimethylsilyl.

y Chemical group not applicable/identifiable.

${ }^{\mathrm{z}}$ Absolutely identified metabolites. 
TABLE 4. Effect of biochar on seedling length, disease severity, and incidence, and Rhizoctonia solani copy numbers on seedlings and in the soilless potting substrate $^{\mathrm{u}}$

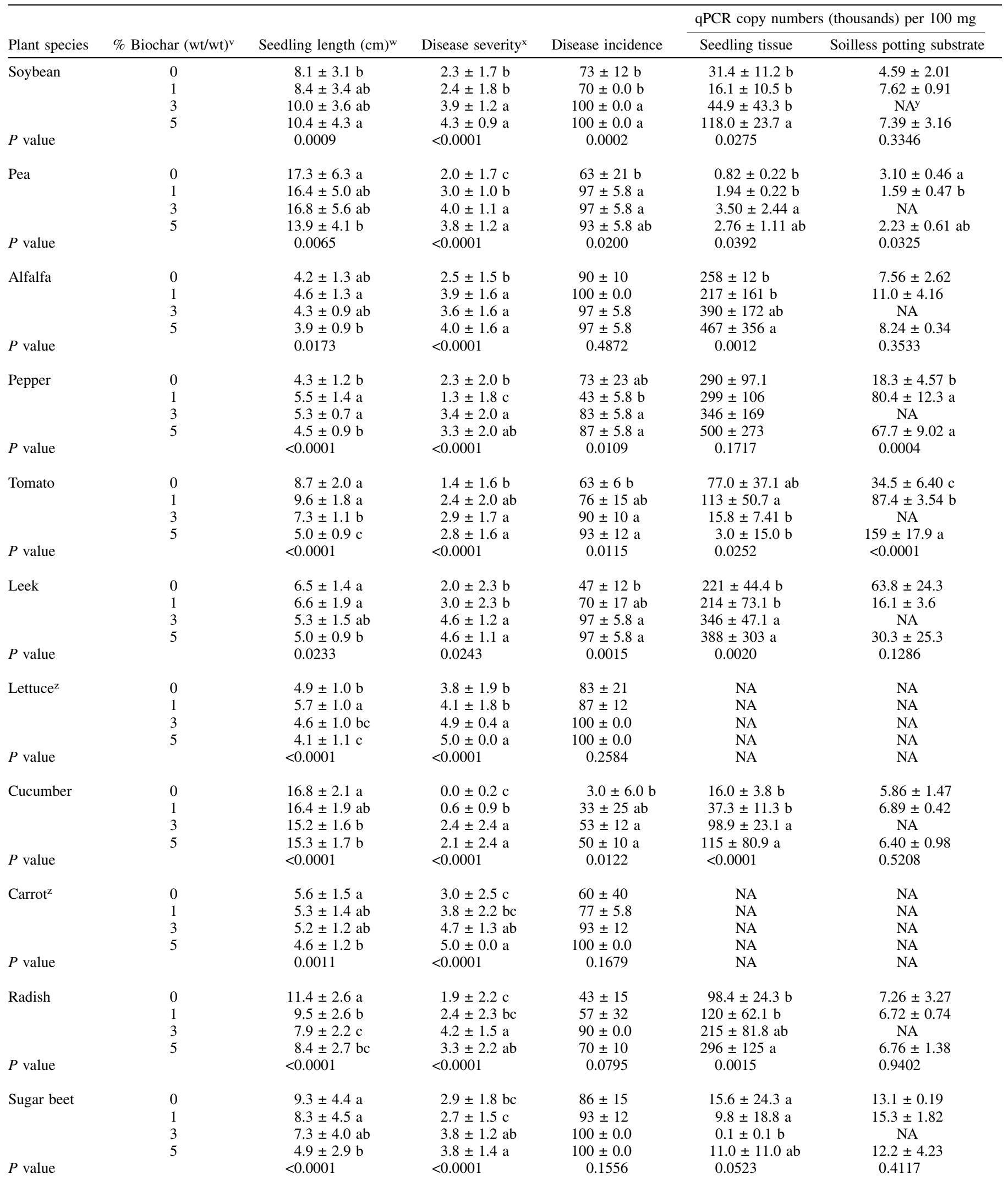

u Numbers represent the mean \pm standard deviation of six replicates of 10 seedlings per petri dish per treatment $(n=6)$ for seedling length, disease score and disease incidence, or the average of six samples for qPCR copy numbers $(n=6)$. Letters represent significant differences within columns for each species according to Tukey's HSD at $\alpha=0.05$ unless otherwise stated.

$\checkmark$ Percent biochar $(\mathrm{wt} / \mathrm{wt})$ applied to the soilless potting substrate.

${ }^{w}$ Mean seedling length of healthy seedlings. Due to high disease incidence and severe plant wilting, the length of diseased plants could not be reliably taken.

x Significant differences based on Mann-Whitney tests at $\alpha=0.05$.

y NA, data not available.

z DNA from carrot and lettuce seedlings was not amplifiable due to high disease severity. 
were performed (principal component analysis [PCA], partial least squares-discriminant analysis [PLS-DA], and PLS-hierarchical cluster analysis [PLS-HCA]) using the SIMCA-P+ software (Umetrics, MKS Instruments Inc., Andover, MA). PLS-DA is a supervised form of discriminant analysis that determines the correlation between variables based on clustering of observations by treatments (Eriksson et al. 2009). The detection of biomarkers was based on PLS-DA regression coefficients and standard errors were calculated using jack-knifing with 95\% confidence intervals (Efron and Gong 1983). PLS-dendrograms were based on scores of PLS regression models (Eriksson et al. 2009) and distances were calculated by using the method of Ward (1963).

Metabolite network analysis. Metabolite fluctuations of $R$. solani in response to biochar in vitro were reconstructed based on pathway data available in the Kyoto Encyclopedia of Genes and Genomes (KEGG) database (http://www.genome.jp/kegg/) and previously published literature. Based on the PLS-DA coefficient plots of pairwise comparisons between 0 and $1 \%, 0$ and 5\%, and 1 and 5\% biochar amendment, $R$. solani metabolomic analyses and the abovementioned sources, key metabolites that were affected in $R$. solani due to biochar amendment were highlighted in the primary metabolic pathways.

Data analyses. One-way analysis of variance and KruskalWallis tests (disease scores only) were performed on experiments 1 and 2 data using the software JMP 8.0 (SAS Institute, Inc., Cary, NC). For samples showing significant differences, Tukey's HSD or Mann-Whitney (disease scores) tests were performed for pairwise comparisons using the software JMP 8.0 (SAS Institute). Homogeneity of variance using the $\chi^{2}$ test was done using the software JMP 8.0 (SAS Institute) to determine if trials could be pooled. Data were $\log (10)$-transformed when required for data normalization.

Discriminant analyses. To detect possible correlations between biochar amendment, $R$. solani disease score and incidence, qPCR copy numbers, seedling length and CFUs from experiment 1 multivariate analyses were performed using the SIMCA-P+ software v.12.0.1.0 (Umetrics). The data matrix was composed of the biological replicates from the different biochar amendment concentrations (columns; $X$ variables) and the variables for plant length, disease score, disease incidence, $R$. solani DNA copy numbers in seedlings and soilless potting substrate, and CFUs for each group of microorganisms (rows; $Y$ variables). For the initial analysis of the data, PCA was performed to identify outliers and trends within the treatments before performing further analyses. To determine the variables that were most affected by increasing biochar concentrations, PLS-DA regression coefficients $(P<0.05)$ were performed by clustering based on biochar concentration. Visualization of correlations between the $X$ and $Y$ variables was done by building of a loading $\mathrm{Bi}$ plots using the pc(corr) (correlation scaled loadings of the correlation between $Y$ variables and $X$ scores based on the variable importance of $X$ as scores and loadings) setting in SIMCA-P+. Mean-centering and unit variance (UV) scaling were used for data normalization.

\section{RESULTS}

Biochar physiochemical characteristics. Maple bark biochar consists primarily of carbon (405,666 ppm), calcium (158,945 ppm), potassium (13,507 ppm), hydrogen (12,333 ppm), and nitrogen $(5,000 \mathrm{ppm})$. The $\mathrm{C}: \mathrm{N}$ ratio for the biochar was $81: 1$, illustrative of the high carbon content typically found in biochars. The biochar had only trace concentrations of lead $(4.3 \mathrm{ppm})$, cadmium $(0.78$ ppm), barium (339 ppm), beryllium $(<0.2 \mathrm{ppm})$, arsenic $(<2 \mathrm{ppm})$, and antimony $(<2 \mathrm{ppm})$. A complete elemental characterization is presented in Supplementary Table S1. The initial biochar $\mathrm{pH}$, cation exchange capacity (CEC), and electrical conductivity (EC) were all high (Table 2). When added to the potting substrate, biochar significantly increased the media's $\mathrm{pH}$ by 1.2 -fold and water holding capacity by 2.4 -fold, while EC significantly decreased by 0.58 fold (Table 2). No significant effect on CEC was observed (Table 2). The GC/MS analysis revealed a number of organic compounds belonging to different chemical classes with amines and phenolics accounting for the least abundant, and carboxylic acids, carbohydrates, and fatty acids being the main constituents (Table 3 ).

Plant inoculation and damping-off evaluation. Experiment 1. Amending the soilless potting substrate with greater concentrations of biochar (3 and 5\%) significantly increased damping-off severity in all seedlings except for pepper when compared with control treatments in which biochar was not added (Table 4). A $1 \%$ biochar amendment had varying effects on $R$. solani disease severity, but did not decrease disease (Table 4). Additionally, percent disease incidence in 5 of 11 plant species significantly increased in substrates amended with 3 and $5 \%$ biochar, while in the remaining plant species, biochar amendments had no effect on disease incidence despite an increase in disease severity. In the absence of $R$. solani, seedling length of most plant species was significantly lower at the greatest biochar amendment compared with those grown without amendments (Table 4). Quantification of $R$. solani in seedlings using qPCR provided varied results, while copy numbers in the potting substrate were generally unaffected by biochar amendment (Table 4).

Experiment 2. Exposing R. solani to biochar in vitro prior to inoculating plants increased disease severity in sugar beet and soybean seedlings (Table 5). Disease incidence was increased in sugar beet at $5 \%$ biochar, however, was unaffected in soybean (Table 5).

Culturable microbe abundances. Changes in the abundance of CFUs per gram of soilless potting substrate varied depending on the plant species and biochar concentration (Supplementary Tables S2 and S3). Increasing biochar amendment typically showed significantly greater numbers of bacterial CFUs and lower CFU numbers of filamentous fungi of the majority of plant species. In the case of actinomycetes and yeasts, no clear trends in CFU numbers were observed in substrates amended or not with biochar. Similar trends were observed between treatments with and without $R$. solani inoculation and as such only results for CFUs from soilless potting

TABLE 5. Effect of biochar on Rhizoctonia solani virulence in a soilless potting substratey

\begin{tabular}{|c|c|c|c|c|}
\hline \multirow[b]{2}{*}{$\%$ biochar $(\mathrm{wt} / \mathrm{vol})^{\mathrm{z}}$} & \multicolumn{2}{|c|}{ Soybean } & \multicolumn{2}{|c|}{ Sugar beet } \\
\hline & Disease severity & Disease incidence & Disease severity & Disease incidence \\
\hline 0 & $1.6 \pm 1.2 \mathrm{~b}$ & $70 \pm 10$ & $1.4 \pm 1.5 \mathrm{~b}$ & $50 \pm 20 b$ \\
\hline 1 & $2.5 \pm 1.5 \mathrm{a}$ & $83 \pm 15$ & $2.2 \pm 1.6 \mathrm{ab}$ & $70 \pm 10 a b$ \\
\hline 3 & $3.1 \pm 1.4 \mathrm{a}$ & $90 \pm 10$ & $2.1 \pm 1.4 \mathrm{ab}$ & $70 \pm 0.0 \mathrm{ab}$ \\
\hline 5 & $3.0 \pm 1.3 \mathrm{a}$ & $93 \pm 11$ & $2.7 \pm 1.2 \mathrm{a}$ & $83 \pm 5.8 \mathrm{a}$ \\
\hline$P$ value & 0.0002 & 0.1592 & 0.0391 & 0.0452 \\
\hline
\end{tabular}

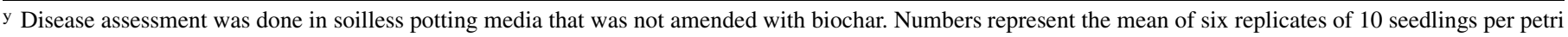
dish per treatment $(n=6)$ for disease score and disease incidence. Letters represent significant differences within columns according to Tukey's HSD test at $\alpha=0.05$.

$\mathrm{z}$ The percent biochar represents the biochar concentration (wt/vol) in WA media in which $R$. solani was exposed to prior to infecting the plants. 
substrate inoculated with $R$. solani are presented in the PLS-DA analyses.

Discriminant analyses. PLS-DA loading Bi plots demonstrated that several trends could be observed between increasing biochar amendment concentrations and the various variables irrespective of the plant species (Fig. 1). Components 1 and 2 of the models explained 67 to $87 \%$ of the original data variance.
Typically, the components separated the biochar treatments by concentration, with component 1 separating the control $(0 \%)$ and the $1 \%$ biochar amendment treatments from the 3 and $5 \%$ biochar treatments (Fig. 1). Strong positive correlations were generally observed with increasing biochar concentrations and disease severity, disease incidence, bacteria and actinomycete CFUs, and potting substrate $\mathrm{pH}$ and $\mathrm{EC}$; however, the strength of these correlations were
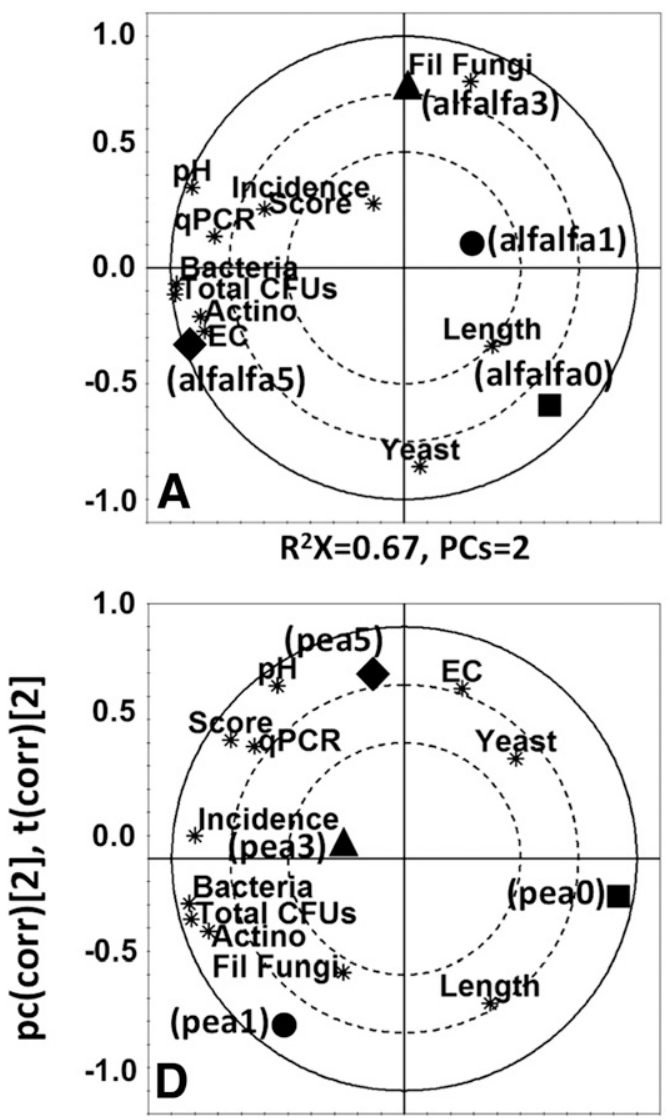

$\mathrm{R}^{2} \mathrm{X}=0.71, \mathrm{PCs}=2$

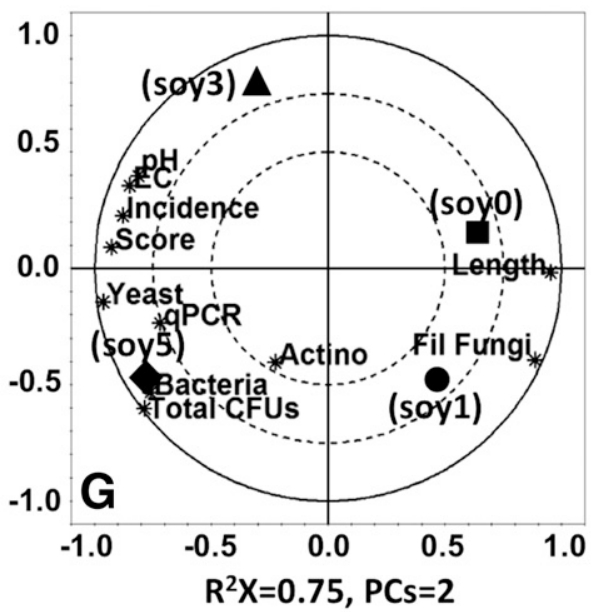

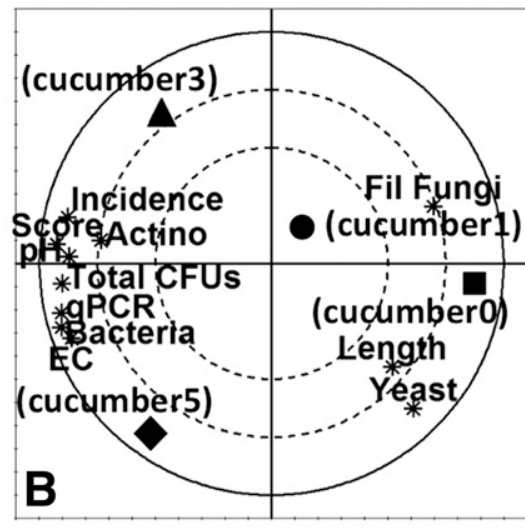

$R^{2} X=0.78, P C s=2$

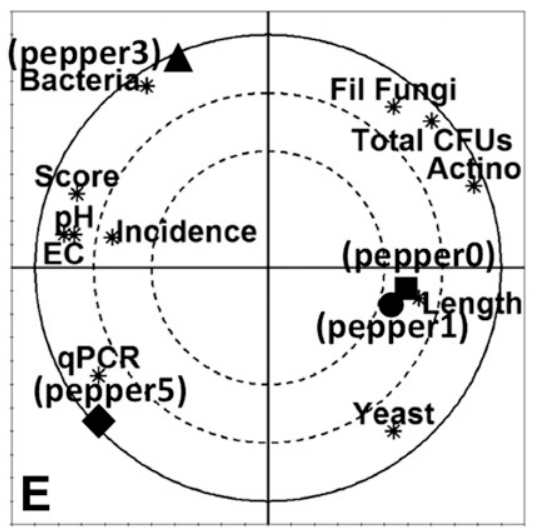

$R^{2} X=0.73, P C s=2$

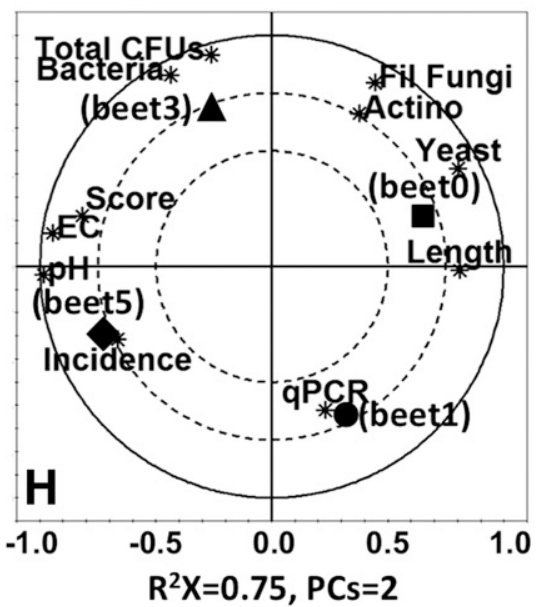

pc(corr) [1], t(corr)[1]

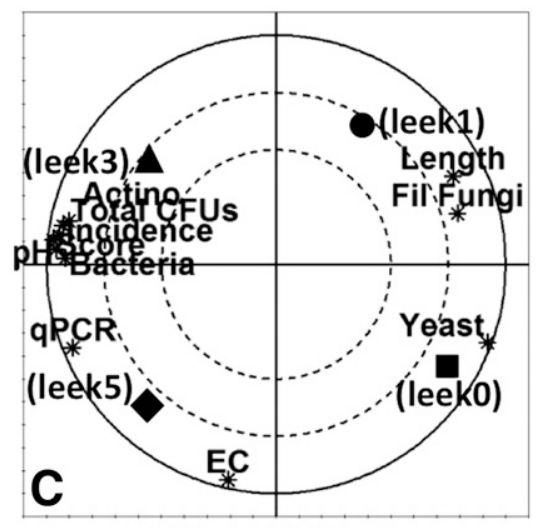

$\mathrm{R}^{2} \mathrm{X}=0.87, \mathrm{PCs}=2$

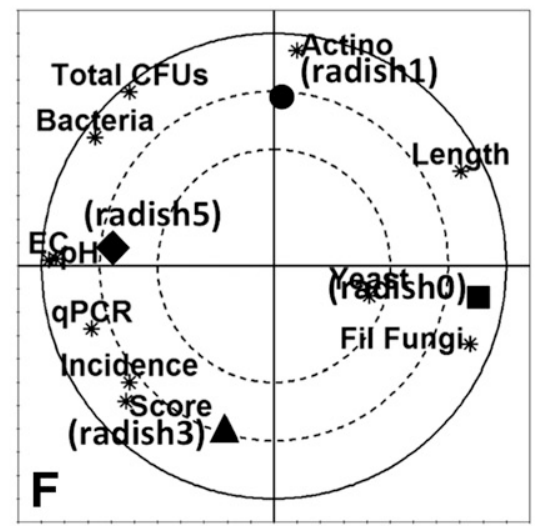

$R^{2} X=0.76, P C s=2$

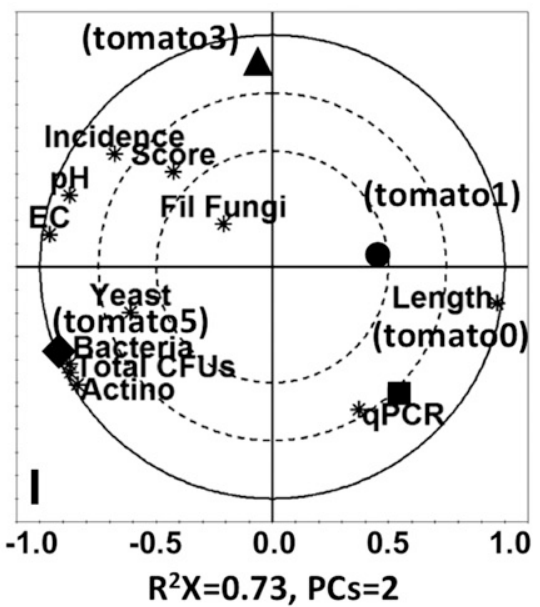

Fig. 1. Loading Bi plots for the effect of varying biochar concentrations on multiple variables in $\mathbf{A}$, alfalfa, B, cucumber, C, leek, D, pea, E, pepper, F, radish, $\mathbf{G}$, soybean, $\mathbf{H}$, sugar beet, and I, tomato, with potting media amended at $0 \%$ (circle), $1 \%$ (square), 3\% (triangle), or 5\% (diamond) biochar (wt/wt) $(P<0.05)$. The scaled loading vectors $\mathrm{pc}$ (corr) and $\mathrm{t}$ (corr) are displayed for the first and second components. Outer ellipses represent the Hotelling $\mathrm{T}^{2}$ at a $95 \%$ confidence interval. The fraction of the sum of squares for the first two principal components is represented by $\mathrm{R}^{2} \mathrm{X}$. Actino, average actinomycetes CFUs; bacteria, average bacteria CFUs; EC, average electrical conductivity of the soilless potting substrate at the end of the experiment; Fil fungi, average filamentous fungi CFUs; Incidence, average disease incidence on seedlings; Length, average length $(\mathrm{cm})$ of healthy seedlings; $\mathrm{pH}$, average $\mathrm{pH}$ of the soilless potting substrate at the end of the experiment; qPCR, average qPCR copy numbers of $R$. solani on diseased seedlings; Severity, average disease severity on seedlings; Total CFUs, average sum of all microbe CFUs; Yeast, average yeast CFUs. 
plant species-dependent. Negative correlations were generally observed with seedling length and yeast and filamentous fungi CFUs (Fig. 1).

Effect of biochar on $R$. solani growth and metabolism. Water agar amended with biochar showed significant increases in the linear extension and growth rate of $R$. solani at all biochar amendments after $12 \mathrm{~h}$ of growth when compared with the control (Table 6). The growth rate of $R$. solani grown on WA amended with different concentrations of biochar was fast (Table 6) with colony growth reaching the edge of the plate by $36 \mathrm{~h}$ compared with $72 \mathrm{~h}$ in nonamended WA plates (data not shown). Likewise, linear hyphal extension of cultures grown in vitro had fold-increases of 1.3, 1.5, and 1.4 for 1,3 , and 5\% biochar amendment, respectively, at $12 \mathrm{~h}$ postinoculation, and 1.7- and 1.5-fold increases for all biochar concentrations at 24 and $36 \mathrm{~h}$, respectively, when compared with the control without biochar amendment (data not shown).

Hyphal dry mass significantly increased when $R$. solani was grown on 1,3, and 5\% biochar amended WA plates at $48 \mathrm{~h}$, while increases in hyphal dry mass at 72 and $120 \mathrm{~h}$ were only observed with 3 and 5\% biochar treatments when compared with control treatments (Tukey's HSD, $\alpha=0.01$ ) (Table 6).

The GC/MS metabolite profiles revealed fluctuations of $R$. solani metabolism in response to the various biochar concentrations as is indicated by the changes in the relative concentration of the recorded metabolic features (Supplementary Fig. S1). PCA was initially applied revealing no outliers and trends among the recorded profiles based on the treatments (data not shown). For the discovery of trends and biomarkers, PLS-DA was performed revealing substantial differences between the metabolic profiles of $R$. solani following exposure to different biochar concentrations and the control, as indicated by the corresponding distances in the PLS-DA PC1/PC2 score plot (Fig. 2A). Three distinct tight clusters were observed, one representing the $R$. solani metabolic profile when grown without biochar and the other two distinct clusters when grown on 1 and 5\% biochar amendment. In agreement with PLS-DA, hierarchical cluster analysis (HCA) applied on the same dataset revealed consistent clustering of the metabolic profiles of $R$. solani grown with and without biochar (Fig. 2B). The GC/MS metabolite profiles of $R$. solani grown on $1 \%$ biochar were more similar to those of $R$. solani grown without biochar. Spectra of $R$. solani grown on the highest biochar concentration had the greatest distance from the control.

In order to detect the most influential metabolites for the observed discrimination between the treatments, PLS-DA was performed by pairwise comparisons (i.e., two way comparisons [0\% versus $1 \%$, $0 \%$ versus $5 \%$, and $1 \%$ versus $5 \%]$ ). Based on the scaled PLS regression coefficients, compounds belonging to carbohydrates, sugar alcohols and amino acids were identified as biomarkers for the observed separations (Fig. 3). The relative concentration of metabolites in the hyphae such as, serine, L-alanine, phenylalanine and malic acid, decreased following biochar amendment. Several metabolites detected in $R$. solani hyphae grown in nonamended plates were absent or below the limit of detection in hyphae grown on biochar-amended plates.
These metabolites include the amino acids glycine and L-tyrosine, and the carboxylic acids fumaric acid and lactic acid.

Metabolite network analysis. Biochar amendment of culture media caused a general fluctuation of $R$. solani hyphal primary metabolism including the tricarboxylic acid (TCA) and mannitol cycles, as well as the glycolysis pathway (Fig. 4). There was an upregulation of the mannitol cycle and a down-regulation of amino acid biosynthesis, glycolysis and the TCA cycle with cultures grown with increasing biochar amendment.

\section{DISCUSSION}

Biochar soil amendment has recently been reported to increase plant resistance to foliar pathogens (Elad et al. 2010; Harel et al. 2012) and decrease disease incidence of soilborne pathogens in several cropping systems although results varied with different types of biochar (Elmer and Pignatello 2011; Jaiswal et al. 2014). The present study is the first to report that maple wood biochar pyrolyzed at high temperature and added to a soilless potting mixture at different concentrations is not only conducive to Rhizoctonia damping-off of a variety of plants, but have a direct effect on the growth rate and metabolism of the pathogen. The increase in damping-off severity and incidence on different seedlings in this
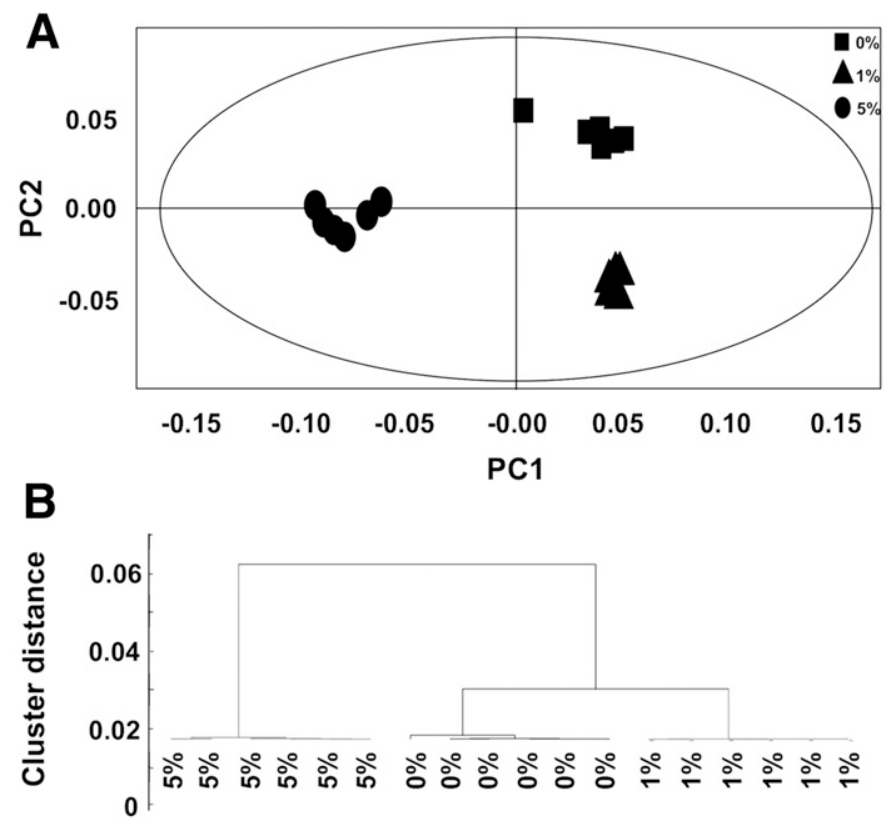

Fig. 2. A, Partial least squares-discriminant analysis (PLS-DA) PC1/PC2 score plot and $\mathbf{B}$, the corresponding PLS-dendrogram for metabolic profiles of Rhizoctonia solani grown in vitro with varying biochar amendment concentrations $(0,1$, or $5 \%, \mathrm{wt} / \mathrm{vol})$. The ellipse represents the Hotelling $\mathrm{T}^{2}$ at a $95 \%$ confidence interval.

TABLE 6. Effect of biochar amendment on in vitro dry mass and growth rate of Rhizoctonia solani

\begin{tabular}{lllrr}
\hline & \multicolumn{3}{c}{ Hyphal dry mass $(\mathrm{mg})^{\mathrm{x}}$} & \multicolumn{1}{c}{ Radial growth rate $\left(\mathrm{mm} \mathrm{h}^{-1}\right)^{\mathrm{z}}$} \\
\cline { 2 - 4 }$\%$ biochar $(\mathrm{wt} / \mathrm{vol})^{\mathrm{y}}$ & $0.552 \pm 0.158 \mathrm{~b}$ & $0.688 \pm 0.120 \mathrm{~b}$ & $1.729 \pm 0.148 \mathrm{c}$ & $1.44 \pm 0.29 \mathrm{~b}$ \\
$0 \%$ & $0.747 \pm 0.152 \mathrm{a}$ & $0.719 \pm 0.205 \mathrm{ab}$ & $1.856 \pm 0.195 \mathrm{c}$ & $2.60 \pm 0.21 \mathrm{a}$ \\
$1 \%$ & $0.821 \pm 0.096 \mathrm{a}$ & $0.860 \pm 0.130 \mathrm{a}$ & $3.075 \pm 0.137 \mathrm{~b}$ & $2.49 \pm 0.15 \mathrm{a}$ \\
$3 \%$ & $0.813 \pm 0.087 \mathrm{a}$ & $0.847 \pm 0.150 \mathrm{ab}$ & $4.633 \pm 0.356 \mathrm{a}$ & $<.52 \pm 0.09 \mathrm{a}$ \\
$5 \%$ & 0.0007 & 0.0202 & $<0.0001$ & $<0.0001$ \\
$P$ value & &
\end{tabular}

${ }^{\mathrm{x}}$ Numbers represent the mean dry mass \pm standard deviation for 24 samples. Letters represent significant differences within columns according to Tukey's HSD test at $\alpha=0.01$.

y Percent biochar (wt/vol) in the WA media at $\mathrm{pH} 7.5$.

${ }^{\mathrm{z}}$ Radial growth rate represents the mean radial growth during the linear growth phase between 6 and $36 \mathrm{~h}$ after inoculation of the media. 
study supports recently published results reporting that increasing concentrations of biochar caused an increase in $R$. solani AG-4 damping-off in cucumber (Jaiswal et al. 2014). Furthermore, this study supports previous studies showing that addition of organic soil amendments such as composts, crop residues and organic wastes are conducive to Rhizoctonia damping-off and that disease suppression is influenced by the parent material, chemical composition and concentration of the organic amendment within the potting mixes or soils (Bonanomi et al. 2007; Ghini and Morandi 2006; Pane et al. 2011; Termorshuizen et al. 2006; Tuitert et al. 1998).

Biochar amendment of soils and potting substrates has been reported to increase colony densities of different microbes, in particular those of bacteria and actinomycetes with variable counts for fungi, as observed in the present study and previously published papers (Graber et al. 2010; Kolton et al. 2011; Warnock et al. 2010). Of interest, total number of culturable microbes did not correlate with disease suppressiveness because incidence and severity of $R$. solani AG-4 damping-off in the majority of plant species significantly increased. It is highly probable that the absence of disease suppression by bacteria and actinomycetes may be attributed to (i) a lack of sufficient concentrations of specific taxa known to be antagonistic against $R$. solani, due to the presence of identified inhibitory compounds in maple bark biochar such as benzoic acid, oxalic acid and several fatty acids, or (ii) their inhibitory compounds are adsorbed by the biochar nullifying their ability to inhibit $R$. solani growth (Graber et al. 2010). Considering that only a small percentage of total microbial communities can be cultured on selective media, total microbial activity inferred by the amount of hydrolyzed fluorescein diacetate (FDA) could be a better measure of Rhizoctonia disease suppressiveness than total microbial counts, as FDA activity has been reported to be positively and highly correlated with $R$. solani disease suppressiveness (Ghini and Morandi 2006).

Pathogen growth and virulence can be affected by a wide array of physical and chemical characteristics, including $\mathrm{pH}, \mathrm{EC}$, and stimulatory compounds such as glycerol, oxalic acid, and benzoic acid (Douds et al. 1996; Fries et al. 1997; Matsuzaki et al. 2008; Sunesson et al. 1995). Suppression of $R$. solani damping-off by organic amendments has often been reported to correlate with ecophysiological factors such as $\mathrm{pH}, \mathrm{EC}$, organic matter content, and compost age (Beach 1949; Bonanomi et al. 2007; Casadevall et al. 2003; Ghini and Morandi 2006; Termorshuizen et al. 2006), while high concentrations of calcium, hydrogen, and magnesium decreased the suppressiveness of soils against damping-off (Ghini and Morandi 2006). In this study, $\mathrm{pH}$ and EC were positively correlated with maple bark biochar amendments, as reported in other studies (Kloss et al. 2012; Singh et al. 2010), and appeared to be insufficient to cause suppression of disease and growth of $R$. solani. Calcium, magnesium, hydrogen, and phosphorous were detected in high concentrations in maple bark biochar and therefore may have also played a role in promoting damping-off (Ghini and Morandi 2006). More research into understanding the impact of biochar amendment on $R$. solani AG-4 virulence factors is warranted.

The increase in hyphal growth rate and mass of $R$. solani cultures, in addition to changes in its metabolic profile, may be attributable to one or several organic compounds present in maple bark biochar extract that could be metabolized by $R$. solani leading to increased growth. Metabolites such as oxalic acid, glycerol, benzoic acid, and
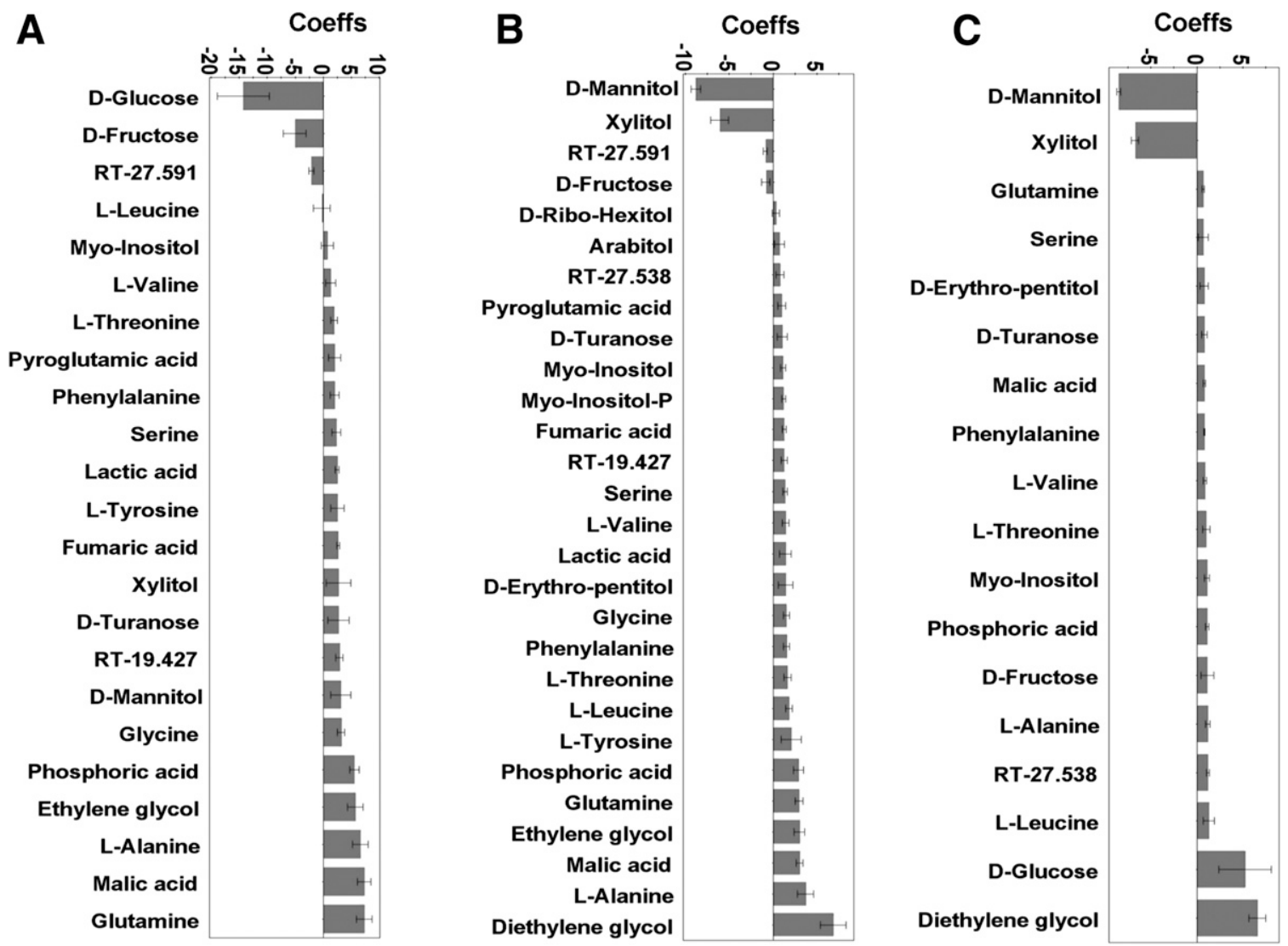

Fig. 3. PLS coefficient plots for GC/MS data matrices of metabolic changes for Rhizoctonia solani grown in vitro with or without biochar amendment with values of scaled and centered PLS regression coefficients (CoeffCS) for the selected metabolites ( $Y$ variables). The most influential variables for treatment separation were selected and are displayed with a 95\% jack-knife confidence interval. Comparisons were made between A, 0 and $1 \%$ biochar amendment, B, 0 and $5 \%$, and $\mathbf{C}, 1$ and 5\% biochar amendment $(\mathrm{wt} / \mathrm{vol})$. Negative values represent metabolites that increased with increasing biochar amendment, while positive values represent metabolites that decreased with increasing biochar amendment. 
ricinoleic acid supplied at low concentration levels have been reported to have a stimulatory effect on fungal growth (Douds et al. 1996; Fries et al. 1997) or are metabolized by fungi (Matsuzaki et al. 2008; Sunesson et al. 1995) and were detected in the maple bark biochar. Notably, glycerol was linked to increased pathogenicity in Fusarium verticilloides and $F$. oxysporum (Cañero and Roncero 2008; Jurado et al. 2008; Rangel et al. 2008). The increase in virulence of $R$. solani AG-4 after having been exposed to biochar for 5 days may be attributable to glycerol and possibly other virulence and/or growth promoting compounds within the biochar.

Changes in $R$. solani metabolites associated with the TCA cycle with biochar amendment demonstrate that $R$. solani is capable of degrading carbon polymers found within the biochar. A decrease in TCA products is often associated with an increased requirement for energy, which is often observed when fungi are subjected to stressful conditions (Harding et al. 2003). However, sufficient glucose supplies in fungi have been reported to cause a reduction in the TCA cycle in Saccharomyces cerevisae (Chambergo et al. 2002). Additionally, high glucose concentrations have been shown to inhibit cellobiohydrolases, the primary fungal enzymes involved in cellulose and lignin degradation (Palonen et al. 2004; Sims et al. 1994), both of which are typically high constituents of biochars (Kang et al. 2012; Qu et al. 2011). The fluctuations of metabolites observed in $R$. solani cultures grown on biochar indicate that the pathogen is utilizing the cellulose, lignin, or possibly other compounds in the biochar, stimulating pathogen growth in the potting mix. Although this merits further investigation, it is common knowledge that $R$. solani is a strong producer of cellulases

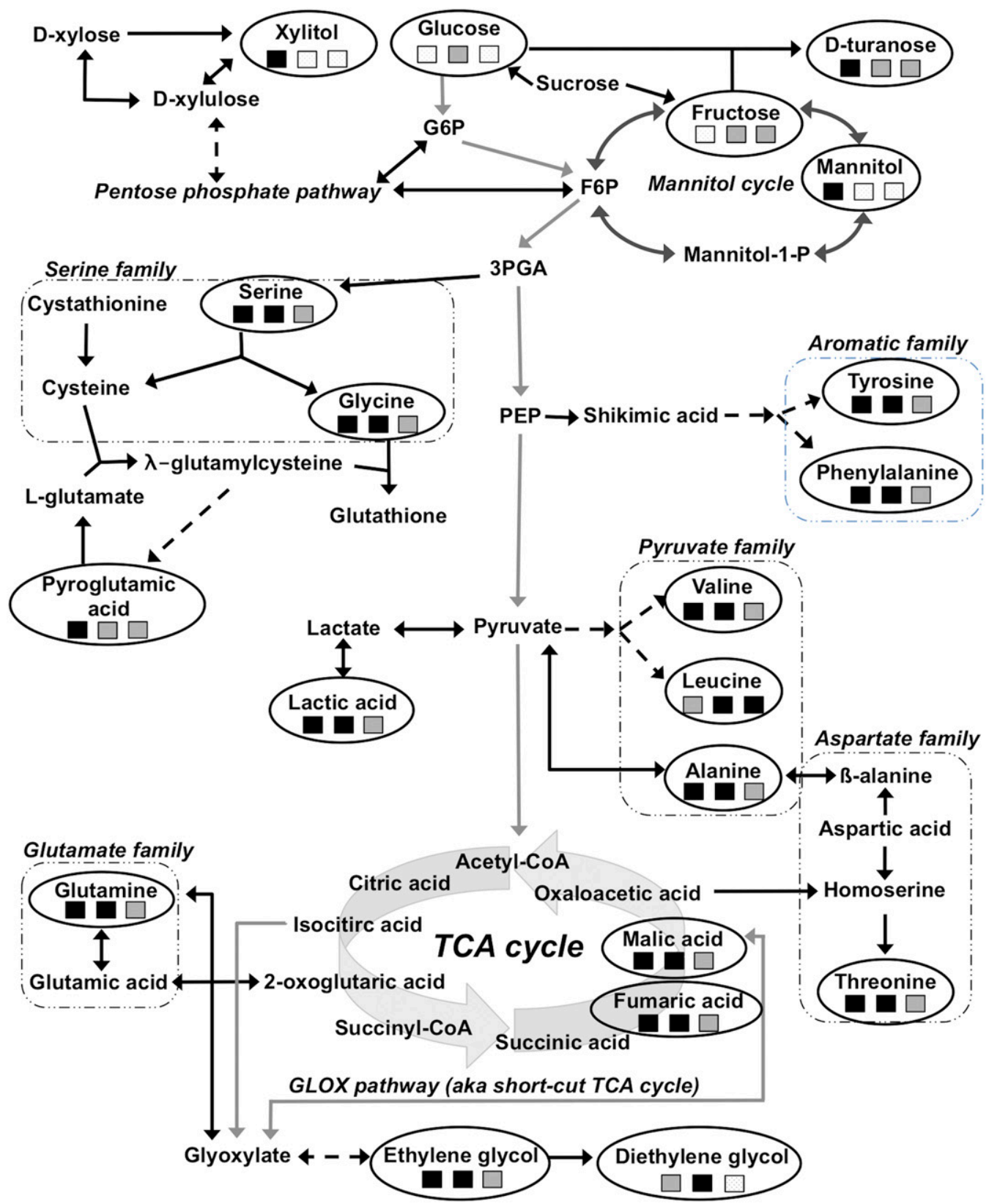

Fig. 4. Fluctuations in Rhizoctonia solani metabolite composition when grown in vitro in the presence or absence of biochar. Metabolite fluctuations are coded based on means of scaled and centered PLS regression coefficients (CoeffCS) from six replications. Dashed lines represent multistep or tentative and not fully elucidated pathways, while solid lines represent one-step reactions. Colors represent significant increases in the metabolite for the given two-way comparisons ( $0 \%$ versus $1 \%, 0 \%$ versus $5 \%$, or $1 \%$ versus $5 \%$ ), where black represents a decrease in the metabolite concentration with increasing biochar concentration, white an increase with increasing biochar concentration, and gray no effect. Boxes under the detected metabolites represent, from left to right, the following two-way comparisons: $0 \%$ versus 1\%, $0 \%$ versus 5\%, and 1\% versus 5\% (3PGA, 3-phosphoglycerate; F6P, fructose-6-phosphate; G6P, glucose-6-phosphate; GLOX, glyoxylate; PEP, phosphoenolpyruvate; TCA, tricarboxylic acid). 
and is able to use cellulose in hardwood bark effectively (Chung et al. 1988).

Xylitol is a precursor of the pentose phosphate pathway, a pathway upstream of the TCA cycle, as well as a major source of reducing power in the form of $\mathrm{NAD}(\mathrm{P}) \mathrm{H}$, reactive oxygen species, and metabolic intermediates such as amino and nucleic acids for biosynthetic processes (Alper and Stephanopoulos 2009; Kruger and von Schaewen 2003; Toivari et al. 2007). It is thus very probable that increased xylitol concentrations in $R$. solani hyphae are an indication of high metabolic activity for amino acid precursors, production of nucleic acids, metabolism of the aromatic compounds from within the biochar to produce reducing power, or the production of precursors for the TCA cycle, which was also affected by exposing $R$. solani to biochar.

Parallel to the increase in xylitol content, an increase of mannitol in hyphal cells of $R$. solani grown on greater biochar concentrations was also observed. Mannitol, a polyol that is not available to plants, has been assigned a multitude of biological roles in saprophytic and pathogenic fungi, including carbohydrate storage, a reservoir of reducing power or to aid in stress tolerance (Solomon et al. 2007). Increased concentrations of mannitol in some pathogenic fungi are implicated as a virulence factor in the opportunistic human pathogen Cryptococcus neoformans against heat and osmotic stress (Casadevall et al. 2003; Chaturvedi et al. 1996) and in the entomopathogenic fungus Metarhizium anisopliae (Rangel et al. 2008; Rangel et al. 2006). Taken together, these results support the potential role of mannitol as a virulence factor or indicator of pathogenicity in $R$. solani since increasing biochar concentrations in WA plates were positively correlated with increased mannitol concentrations in $R$. solani hyphae and also its virulence against several host plants. The exact mechanism of how mannitol modulates virulence is unclear, although the aforementioned potential roles of mannitol may contribute to its role in virulence.

$R$. solani copy numbers in the potting mix were the same for the majority of the plant species and were not affected by the addition of biochar leading us to believe that disease stimulation is not related to an increase in inoculum load but may well be related to alterations in potting substrate structure and bulk density. A decrease in bulk density or an increase in soil particle size gaps led to increased $R$. solani hyphal extension, exploration and spread, but decreased amounts of hyphae (Harris et al. 2003). Biochar amendments are known to increase soil porosity and decrease bulk density (Laird et al. 2010; Oguntunde et al. 2008; Zhang et al. 2010), resulting in the potential for faster hyphal spread of $R$. solani and greater contact of hyphae with roots of the seedlings, resulting in increased disease progression and severity. The potential of biochar to affect fungal growth dynamics may play an important role in microbial ecology and in plant pathology and merits further investigation to determine if particle size and density can be manipulated to help control plant-pathogen interactions.

Biochars may not all equally be suitable as soil amendments, especially if they contain unwanted compounds that may inhibit seed germination or negatively impact seedling growth (Garnett et al. 2004; Hille and Den Ouden 2005). Decreased seedling lengths of 6 of 11 plant species were observed at $5 \%$ biochar amendment and occasionally at 3\% amendment indicating that maple bark biochar has the potential to negatively affect seedling growth. Oxalic acid, benzoic acid, octanoic acid, and some fatty acids, all detected in maple bark biochar, may be considered phytotoxic at certain concentrations not only impacting seedling growth (Kaur and Kaushik 2005; Takijima 1964; Ulbright et al. 1982), but also possibly making them more susceptible to disease. Additionally, changes in microbial communities observed in this study may have had direct effects on plant defense mechanisms and/or $R$. solani growth and virulence factors. In accordance with this notion, defense genes of Arabidopsis grown in biochar-amended potting mix were down-regulated (Viger et al. 2014) possibly reducing a plant's ability to properly defend itself, as observed in our study. Taken together, the increased disease incidence of damping-off in this study was likely due to a combination of factors including decreased seedling growth, increased fungal growth and virulence, and interactions between plants, $R$. solani and other microorganisms present in the potting substrate.

The present study demonstrates for the first time that short-term exposure of seedlings to $R$. solani in biochar amended soilless potting substrates can cause increases in severity and incidence of early stage damping-off in different plant species. Additionally, it is the first to report the effect of biochar on the metabolome of a fungal pathogen. It should be noted that the present study focused on the effect of biochar on one pathogen, albeit with different plant species, and that the effect of maple bark biochar in other soils or potting substrate types as well as on other pathosystems should be examined. Future directions should focus more on plant-pathogen interactions and disease management in response to biochar amendment, as well as attempt to understand the effect of amendments on pathogen growth and physiology. A more in-depth understanding of the factors that affect these interactions is necessary prior to applying biochar to soils or potting substrates in order to limit crop losses.

\section{ACKNOWLEDGMENTS}

We thank H. Lalonde for the CEC analysis as well as W. Hendershot for his insights on soil chemistry, and M. Cubeta for supplying R. solani AG-4 culture. Thanks also go to M. Kaine from Awards Rubber and Plastic Industries, Ltd. for supplying the biochar. This work was supported by the Ministère d'agriculture, pêcheries et alimentation de Québec (MAPAQ), and in part by the Natural Sciences and Engineering Research Council (NSERC).

\section{LITERATURE CITED}

Aliferis, K., and Jabaji, S. 2010. ${ }^{1} \mathrm{H}$ NMR and GC-MS metabolic fingerprinting of developmental stages of Rhizoctonia solani sclerotia. Metabolomics 6:96-108.

Aliferis, K. A., and Jabaji, S. 2012. FT-ICR/MS and GC-EI/MS metabolomics networking unravels global potato sprout's responses to Rhizoctonia solani infection. PLoS One 7:e42576.

Alper, H., and Stephanopoulos, G. 2009. Engineering for biofuels: Exploiting innate microbial capacity or importing biosynthetic potential? Nat. Rev. Microbiol. 7:715-723

Anderson, N. A. 1982. The genetics and pathogenicity of Rhizoctonia solani. Annu. Rev. Phytopathol. 20:329-347.

Bailey, K. L., Gossen, B. D., Gugel, R. K., and Morrall, R. A. A. 2003. Diseases of field crops in Canada, 3rd Ed. The Canadian Phytopathological Society and University Extension Press, Saskatoon, SK.

Beach, W. S. 1949. The effects of excess solutes, temperature and moisture upon damping-off. Vol. 509 of Bulletin. Pennsylvania State College, School of Agriculture, Agricultural Experiment Station, Pennsylvania.

Benhamou, N., Kloepper, J. W., and Tuzun, S. 1998. Induction of resistance against Fusarium wilt of tomato by combination of chitosan with an endophytic bacterial strain: ultrastructure and cytochemistry of the host response. Planta 204:153-168.

Bonanomi, G., Antignani, V., Capodilupo, M., and Scala, F. 2010. Identifying the characteristics of organic soil amendments that suppress soilborne plant diseases. Soil Biol. Biochem. 42:136-144.

Bonanomi, G., Antignani, V., Pane, C., and Scala, F. 2007. Suppression of soilborne fungal diseases with organic amendments. J. Plant Pathol. 89:311-324.

Cañero, D. C., and Roncero, M. 2008. Functional analyses of laccase genes from Fusarium oxysporum. Phytopathology 98:509-518.

Cardoso, J. E., and Echandi, E. 1987. Biological control of Rhizoctonia root rot of snap bean with binucleate Rhizoctonia-like fungi. Plant Dis. 71:167-170.

Casadevall, A., Steenbergen, J. N., and Nosanchuk, J. D. 2003. 'Ready made' virulence and 'dual use' virulence factors in pathogenic environmental fungi-the Cryptococcus neoformans paradigm. Curr. Opin. Microbiol. 6:332-337.

Chambergo, F. S., Bonaccorsi, E. D., Ferreira, A. J., Ramos, A. S., Ferreira, J. R., Abrahao-Neto, J., Farah, J. P. S., and El-Dorry, H. 2002. Elucidation of the metabolic fate of glucose in the filamentous fungus Trichoderma reese $i$ using expressed sequence tag (EST) analysis and cDNA microarrays. J. Biol. Chem. 277:13983-13988.

Chaturvedi, V., Flynn, T., Niehaus, W. G., and Wong, B. 1996. Stress tolerance and pathogenic potential of a mannitol mutant of Cryptococcus neoformans. Microbiology 142:937-943. 
Chen, H., Seguin, P., and Jabaji, S. 2009. Differential expression of genes encoding the phenylpropanoid pathway upon infection of soybean seedlings by Rhizoctonia solani. Can. J. Plant Pathol. 31:356-367.

Chung, Y., Hoitink, H., Dick, W., and Herr, L. 1988. Effects of organic matter decomposition level and cellulose amendment on the inoculum potential of Rhizoctonia solani in hardwood bark media. Phytopathology 78:836-840.

Douds, D., Nagahashi, G., and Abney, G. 1996. The differential effects of cell wall-associated phenolics, cell walls, and cytosolic phenolics of host and non-host roots on the growth of two species of AM fungi. New Phytol. 133: 289-294.

Efron, B., and Gong, G. 1983. A leisurely look at the bootstrap, the jackknife, and cross-validation. Am. Stat. 37:36-48.

Elad, Y., David, D. R., Harel, Y. M., Borenshtein, M., Kalifa, H. B., Silber, A., and Graber, E. R. 2010. Induction of systemic resistance in plants by biochar, a soil-applied carbon sequestering agent. Phytopathology 100:913-921.

Elmer, W. H., and Pignatello, J. J. 2011. Effect of biochar amendments on mycorrhizal associations and Fusarium crown and root rot of asparagus in replant soils. Plant Dis. 95:960-966.

Eriksson, L., Trygg, J., and Wold, S. 2009. PLS-trees, a top-down clustering approach. J. Chemometr. 23:569-580.

Fay, M. F., Swensen, S. M., and Chase, M. W. 1997. Taxonomic affinities of Medusagyne oppositifolia (Medusagynaceae). Kew Bull. 52:111-120.

Fries, L. L., Pacovsky, R. S., Safir, G. R., and Siqueira, J. O. 1997. Plant growth and arbuscular mycorrhizal fungal colonization affected by exogenously applied phenolic compounds. J. Chem. Ecol. 23:1755-1767.

Gagne-Bourgue, F., Aliferis, K., Seguin, P., Rani, M., Samson, R., and Jabaji, S. 2013. Isolation and characterization of indigenous endophytic bacteria associated with leaves of switchgrass (Panicum virgatum L.) cultivars. J. Appl. Microbiol. 114:836-853.

Garnett, E., Jonsson, L. M., Dighton, J., and Murnen, K. 2004. Control of pitch pine seed germination and initial growth exerted by leaf litters and polyphenolic compounds. Biol. Fertil. Soils 40:421-426.

Gavlak, R., Horneck, D., Miller, R. O., and Kotuby-Amacher, J. 2003. Soil, plant and water reference methods for the western region. WREP-125, 2nd ed. WERA-103 Publication, Colorado State University, Ft. Collins.

Ghini, R., and Morandi, M. A. B. 2006. Biotic and abiotic factors associated with soil suppressiveness to Rhizoctonia solani. Sci. Agric. 63:153-160.

Gillman, G., and Sumpter, E. 1986. Modification to the compulsive exchange method for measuring exchange characteristics of soils. Soil Res. 24:61-66.

González García, V., Portal Onco, M. A., and Rubio, S. 1999. Review. Biology and systematics of the form genus Rhizoctonia. Span. J. Agric. Res. 4:55-79.

Graber, E. R., Harel, Y. M., Kolton, M., Cytryn, E., Silber, A., David, D. R., Tsechansky, L., Borenshtein, M., and Elad, Y. 2010. Biochar impact on development and productivity of pepper and tomato grown in fertigated soilless media. Plant Soil 337:481-496.

Gravel, V., Dorais, M., and Ménard, C. 2013. Organic potted plants amended with biochar: Its effect on growth and Pythium colonization. Can. J. Plant Sci. 93:1217-1227.

Harding, H. P., Zhang, Y., Zeng, H., Novoa, I., Lu, P. D., Calfon, M., Sadri, N., Yun, C., Popko, B., and Paules, R. 2003. An integrated stress response regulates amino acid metabolism and resistance to oxidative stress. Mol. Cell 11:619-633.

Harel, Y. M., Elad, Y., Rav-David, D., Borenstein, M., Shulchani, R., Lew, B., and Graber, E. R. 2012. Biochar mediates systemic response of strawberry to foliar fungal pathogens. Plant Soil 357:245-257.

Harris, K., Young, I. M., Gilligan, C. A., Otten, W., and Ritz, K. 2003. Effect of bulk density on the spatial organisation of the fungus Rhizoctonia solani in soil. FEMS Microbiol. Ecol. 44:45-56.

Hille, M., and Den Ouden, J. 2005. Charcoal and activated carbon as adsorbate of phytotoxic compounds-a comparative study. Oikos 108:202-207.

Huang, X., Zhang, N., Yong, X., Yang, X., and Shen, Q. 2012. Biocontrol of Rhizoctonia solani damping-off disease in cucumber with Bacillus pumilus AQR-N43. Microbiol. Res. 167:135-143.

Jaiswal, A. K., Elad, Y., Graber, E. R., and Frenkel, O. 2014. Rhizoctonia solani suppression and plant growth promotion in cucumber as affected by biochar pyrolysis temperature, feedstock and concentration. Soil Biol. Biochem. 69:110-118.

Johanson, A., Turner, H. C., McKay, G. J., and Brown, A. E. 1998. A PCRbased method to distinguish fungi of the rice sheath-blight complex, Rhizoctonia solani, $R$. oryzae and $R$. oryzae-sativae. FEMS Microbiol. Lett. 162:289-294.

Jurado, M., Marín, P., Magan, N., and González-Jaén, M. T. 2008. Relationship between solute and matric potential stress, temperature, growth, and FUM1 gene expression in two Fusarium verticillioides strains from Spain. Appl. Environ. Microbiol. 74:2032-2036.

Kang, S., Li, X., Fan, J., and Chang, J. 2012. Characterization of hydrochars produced by hydrothermal carbonization of lignin, cellulose, D-xylose, and wood meal. Ind. Eng. Chem. Res. 51:9023-9031.
Kaur, H., and Kaushik, S. 2005. Cellular evidence of allelopathic interference of benzoic acid to mustard (Brassica juncea L.) seedling growth. Plant Physiol. Biochem. 43:77-81.

Khodadad, C. L., Zimmerman, A. R., Green, S. J., Uthandi, S., and Foster, J. S. 2011. Taxa-specific changes in soil microbial community composition induced by pyrogenic carbon amendments. Soil Biol. Biochem. 43:385-392. Kloss, S., Zehetner, F., Dellantonio, A., Hamid, R., Ottner, F., Liedtke, V., Schwanninger, M., Gerzabek, M. H., and Soja, G. 2012. Characterization of slow pyrolysis biochars: Effect of feedstocks and pyrolysis temperature on biochar properties. J. Environ. Qual. 41:990-1000.

Kolton, M., Harel, Y. M., Pasternak, Z., Graber, E. R., Elad, Y., and Cytryn, E. 2011. Impact of biochar application to soil on the root-associated bacterial community structure of fully developed greenhouse pepper plants. Appl. Environ. Microbiol. 77:4924-4930.

Kruger, N. J., and von Schaewen, A. 2003. The oxidative pentose phosphate pathway: Structure and organisation. Curr. Opin. Plant Biol. 6:236-246

Laird, D. A., Fleming, P., Davis, D. D., Horton, R., Wang, B., and Karlen, D. L. 2010. Impact of biochar amendments on the quality of a typical Midwestern agricultural soil. Geoderma 158:443-449.

Lehmann, J., Gaunt, J., and Rondon, M. 2006. Bio-char sequestration in terrestrial ecosystems-A review. Mitig. Adapt. Strategies Glob. Change 11: 395-419.

Lehmann, J., and Joseph, S. 2009. Biochar for Environmental Management: Science and Technology. Earthscan Publishers, Ltd., London, UK.

Matsuzaki, F., Shimizu, M., and Wariishi, H. 2008. Proteomic and metabolomic analyses of the white-rot fungus Phanerochaete chrysosporium exposed to exogenous benzoic acid. J. Proteome Res. 7:2342-2350.

Montealegre, J. R., Reyes, R., Pérez, L. M., Herrera, R., Silva, P., and Besoain, X. 2003. Selection of bioantagonistic bacteria to be used in biological control of Rhizoctonia solani in tomato. Electron. J. Biotechnol. 6:115-127.

Oguntunde, P. G., Abiodun, B. J., Ajayi, A. E., and van de Giesen, N. 2008. Effects of charcoal production on soil physical properties in Ghana. J. Plant Nutr. Soil Sci. 171:591-596.

Palonen, H., Tjerneld, F., Zacchi, G., and Tenkanen, M. 2004. Adsorption of Trichoderma reesei $\mathrm{CBH}$ I and EG II and their catalytic domains on steam pretreated softwood and isolated lignin. J. Biotechnol. 107:65-72.

Pane, C., Spaccini, R., Piccolo, A., Scala, F., and Bonanomi, G. 2011. Compost amendments enhance peat suppressiveness to Pythium ultimum, Rhizoctonia solani and Sclerotinia minor. Biol. Control 56:115-124.

Qu, T., Guo, W., Shen, L., Xiao, J., and Zhao, K. 2011. Experimental study of biomass pyrolysis based on three major components: Hemicellulose, cellulose, and lignin. Ind. Eng. Chem. Res. 50:10424-10433.

Rangel, D. E., Alston, D. G., and Roberts, D. W. 2008. Effects of physical and nutritional stress conditions during mycelial growth on conidial germination speed, adhesion to host cuticle, and virulence of Metarhizium anisopliae, an entomopathogenic fungus. Mycol. Res. 112:1355-1361.

Rangel, D. E., Anderson, A. J., and Roberts, D. W. 2006. Growth of Metarhizium anisopliae on non-preferred carbon sources yields conidia with increased UV-B tolerance. J. Invertebr. Pathol. 93:127-134.

Rawls, W., Brakensiek, D., and Saxton, K. 1982. Estimation of soil water properties. Trans. ASAE 25:1316-1320.

Rillig, M. C., Wagner, M., Salem, M., Antunes, P. M., George, C., Ramke, H.-G., Titirici, M.-M., and Antonietti, M. 2010. Material derived from hydrothermal carbonization: Effects on plant growth and arbuscular mycorrhiza. Appl. Soil Ecol. 45:238-242.

Sansone, S.-A., Fan, T., Goodacre, R., Griffin, J. L., Hardy, N. W., Kaddurah-Daouk, R., Kristal, B. S., Lindon, J., Mendes, P., and Morrison, N. 2007. The metabolomics standards initiative. Nat. Biotechnol. 25:846-848.

Scheuerell, S. J., Sullivan, D. M., and Mahaffee, W. F. 2005. Suppression of seedling damping-off caused by Pythium ultimum, P. irregulare, and Rhizoctonia solani in container media amended with a diverse range of Pacific Northwest compost sources. Phytopathology 95:306-315.

Sims, P. F., Soares-Felipe, M. S., Wang, Q., Gent, M. E., Tempelaars, C., and Broda, P. 1994. Differential expression of multiple exo-cellobiohydrolase I-like genes in the lignin-degrading fungus Phanerochaete chrysosporium. Mol. Microbiol. 12:209-216.

Singh, B., Singh, B. P., and Cowie, A. L. 2010. Characterisation and evaluation of biochars for their application as a soil amendment. Soil Res. 48:516-525.

Sohi, S., Krull, E., Lopez-Capel, E., and Bol, R. 2010. A review of biochar and its use and function in soil. Adv. Agron. 105:47-82.

Solomon, P. S., Waters, O. D., and Oliver, R. P. 2007. Decoding the mannitol enigma in filamentous fungi. Trends Microbiol. 15:257-262.

Sunesson, A., Vaes, W., Nilsson, C., Blomquist, G., Andersson, B., and Carlson, R. 1995. Identification of volatile metabolites from five fungal species cultivated on two media. Appl. Environ. Microbiol. 61:2911-2918.

Takijima, Y. 1964. Studies on organic acids in paddy field soils with reference to their inhibitory effects on the growth of rice plants: Part 1. Growth inhibiting action of organic acids and absorption and decomposition of them by soils. Soil Sci. Plant Nutr. 10:14-21. 
Termorshuizen, A., Van Rijn, E., Van der Gaag, D., Alabouvette, C., Chen, Y., Lagerlöf, J., Malandrakis, A., Paplomatas, E., Rämert, B., and Ryckeboer, J. 2006. Suppressiveness of 18 composts against 7 pathosystems: Variability in pathogen response. Soil Biol. Biochem. 38:2461-2477.

Toivari, M. H., Ruohonen, L., Miasnikov, A. N., Richard, P., and Penttilä, M. 2007. Metabolic engineering of Saccharomyces cerevisiae for conversion of D-glucose to xylitol and other five-carbon sugars and sugar alcohols. Appl. Environ. Microbiol. 73:5471-5476.

Tuitert, G., Szczech, M., and Bollen, G. J. 1998. Suppression of Rhizoctonia solani in potting mixtures amended with compost made from organic household waste. Phytopathology 88:764-773.

Ulbright, C. E., Pickard, B. G., and Varner, J. E. 1982. Effects of short chain fatty acids on radicle emergence and root growth in lettuce. Plant Cell Environ. 5:293-301.

Van Peer, R., Niemann, G., and Schippers, B. 1991. Induced resistance and phytoalexin accumulation in biological control of Fusarium wilt of carnation by Pseudomonas sp. strain WCS417r. Phytopathology 81:728-734.
Viger, M., Hancock, R. D., Miglietta, F., and Taylor, G. 2014. More plant growth but less plant defence? First global gene expression data for plants grown in soil amended with biochar. GCB Bioenergy 7:658-672.

Ward, J. H., Jr. 1963. Hierarchical grouping to optimize an objective function. J. Am. Stat. Assoc. 58:236-244.

Warnock, D. D., Mummey, D. L., McBride, B., Major, J., Lehmann, J., and Rillig, M. C. 2010. Influences of non-herbaceous biochar on arbuscular mycorrhizal fungal abundances in roots and soils: Results from growthchamber and field experiments. Appl. Soil Ecol. 46:450-456.

White, T., Bruns, T., Lee, S., and Taylor, J. 1990. Amplification and direct sequencing of fungal ribosomal RNA genes for phylogenetics. Pages 315-322 in: PCR Protocols: A Guide to Methods and Applications. M. A. Innis, D. H. Gelfand, J. J. Sinsky, and T. J. White, eds. Academic Press, New York.

Zhang, A., Cui, L., Pan, G., Li, L., Hussain, Q., Zhang, X., Zheng, J., and Crowley, D. 2010. Effect of biochar amendment on yield and methane and nitrous oxide emissions from a rice paddy from Tai Lake plain, China. Agric. Ecosyst. Environ. 139:469-475. 